



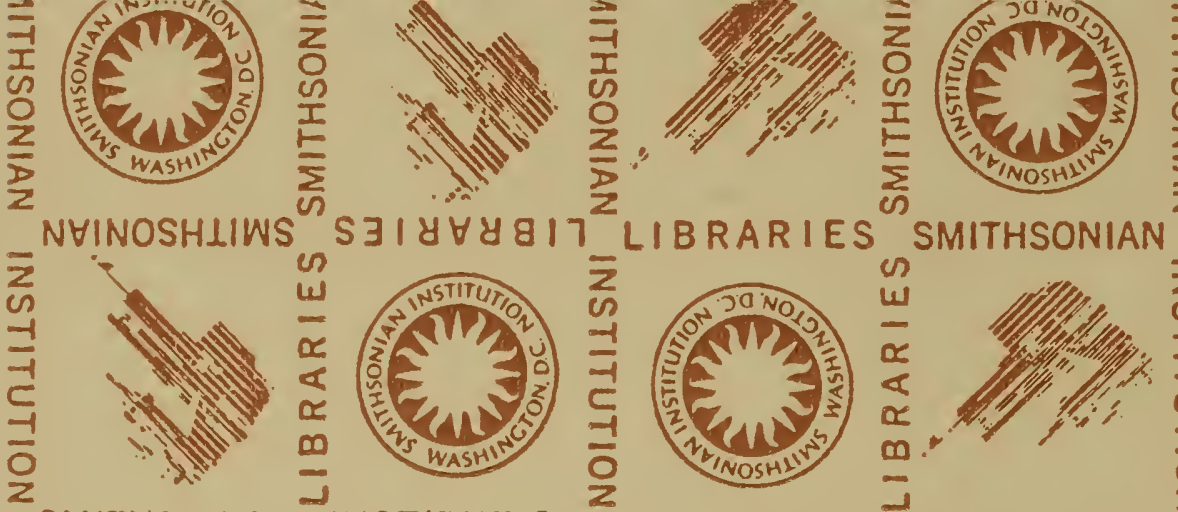

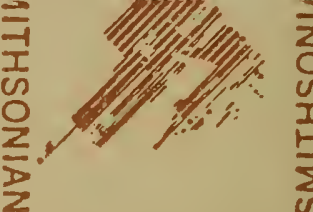
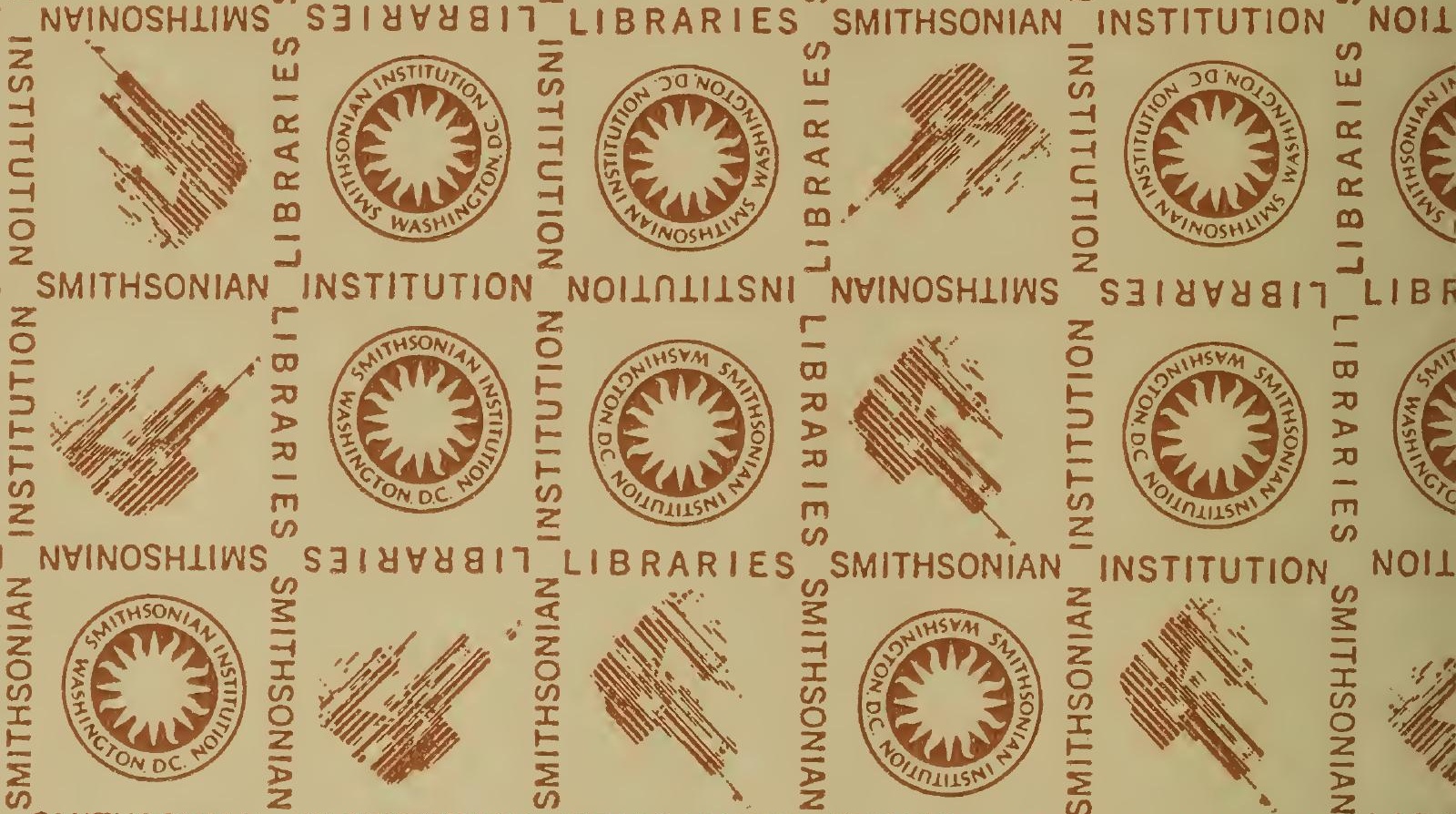

NOIL

ARIES SMITHSONIAN
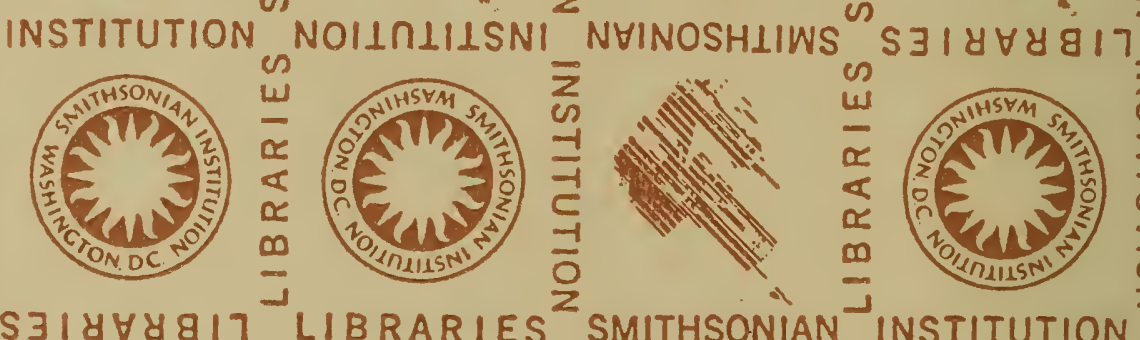

LIB F
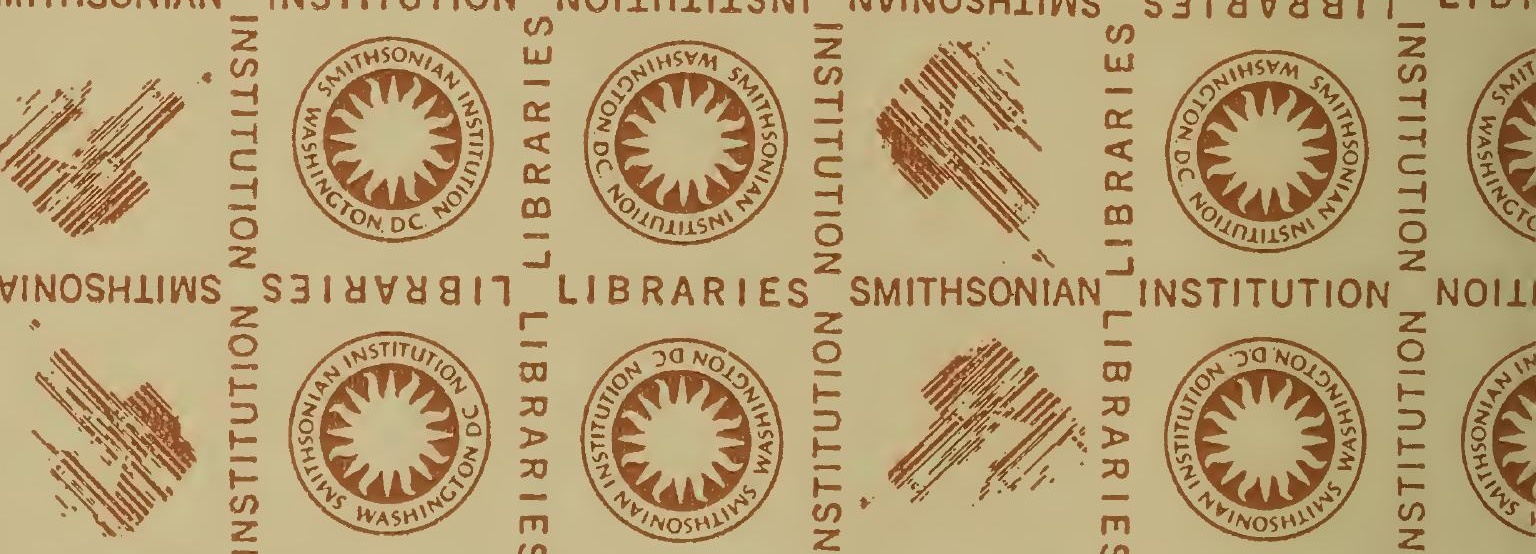

NOI 1
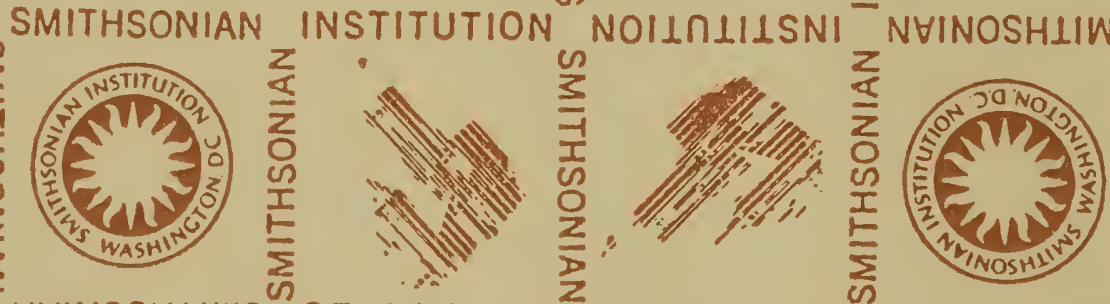

in
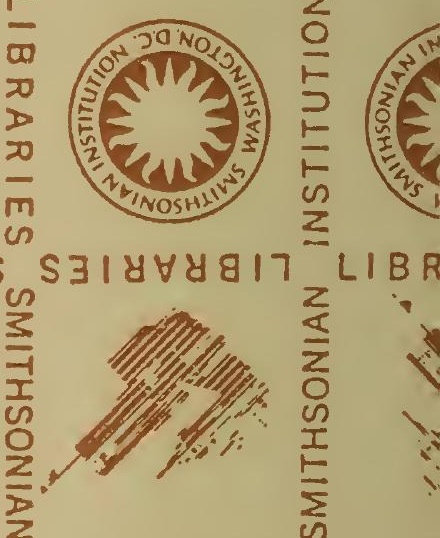

LIBR
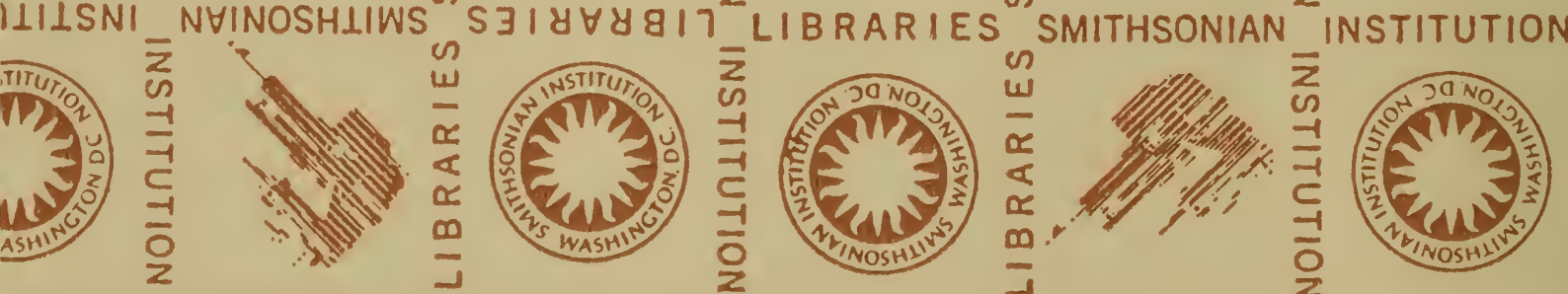

NOII
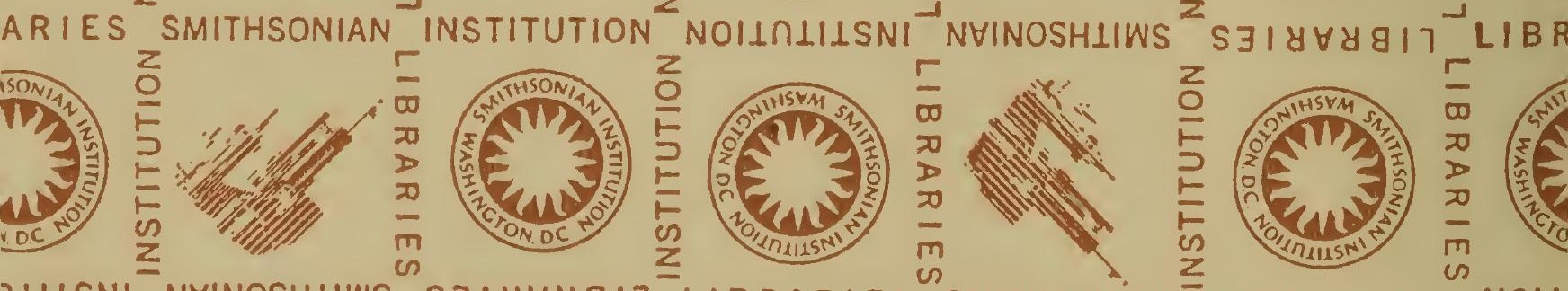



\section{BATIKS, AND \\ HOW TO MAKE THEM}






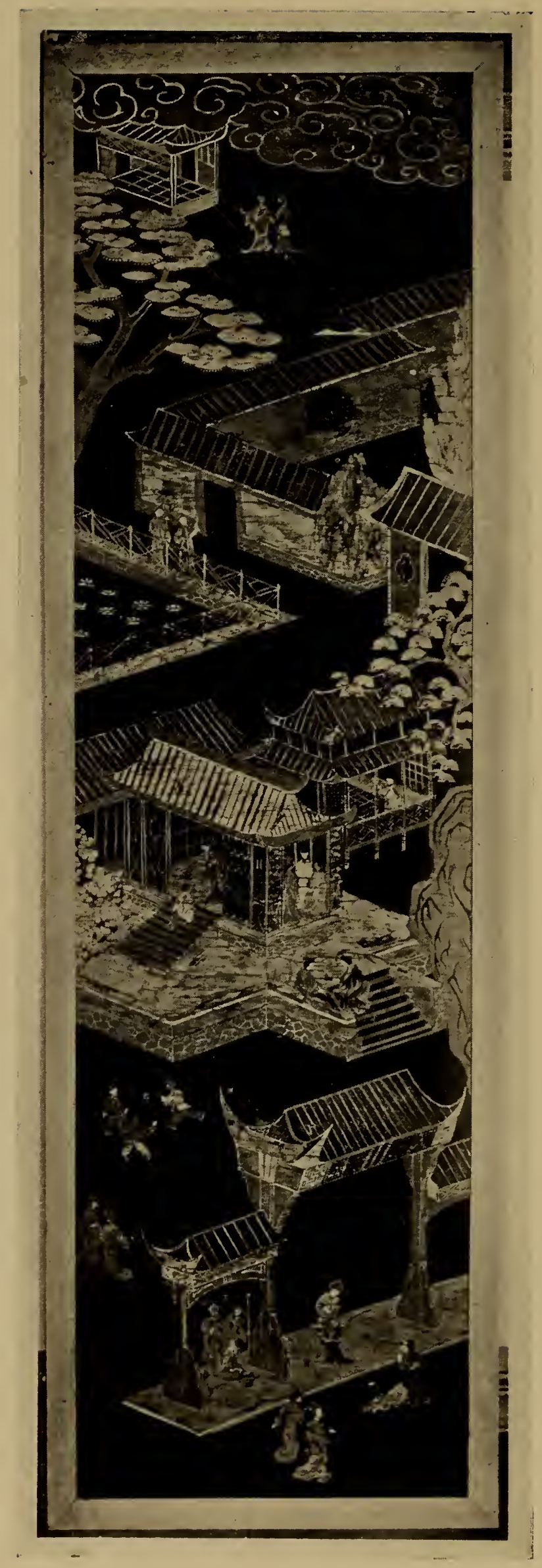

CHINESE SCREEN PANEL BY PIETER MIJER AND FMILE WEECKERS 


\title{
BATIKS, AND \\ HOW TO MAKE THEM
}

\author{
BY \\ PIETER MIJER
}

WITH ILLUSTRATIONS

From Photographs by

G. W. Harting

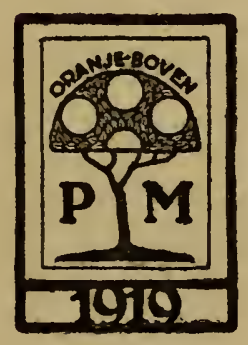

NEW YORK

DODD, MEAD AND COMPANY

1921 

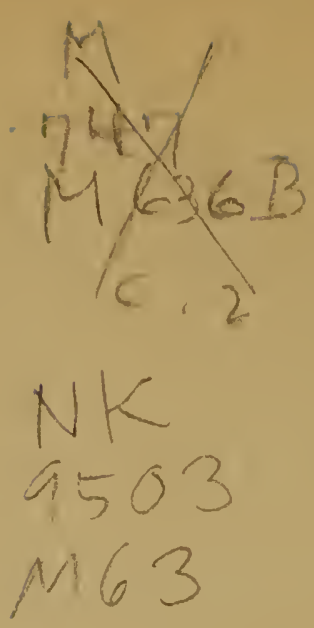

OOPYRIGHT, 1919

BY DODD, MEAD AND COMPANY, INO.

First edition printed June, 1919

Second edition printed August, 1919

Third edition printed December, 1919

Fourth edition printed September, 1920 


\section{FOREWORD}

In writing the following pages on "Batiks, and how they are made" I had a double purpose in view. First, to make this ancient art more known to the public in general and to the many textile craftworkers in particular; secondly, to try to give some practical advice which will make for the better execution of the work.

Batik is not so crude a method of decorating material as many people have thought it to be. It is not a matter of smearing some wax on a piece of material with any old brush, dipping it haphazard into any kind of dye, leaving it to the gods to decide what colour it is going to be, and finally trying to sell it as a high-priced work of art. On the contrary, it is a craft which requires quite a good deal of skill and knowledge of design, as well as a good idea of colour. 
vi

The batik art has been much abused and it may be of interest to many to know something of its history, to read the description of the process as practised by the natives of Java, the method used in Holland, and the means now employed by some craftsmen and women in America.

Too much stress cannot be laid on the fact that it is, as a rule, the small details that many people like to overlook because they seem of comparatively little importance, that bring out the charm and beauty of a real batik. Batik is not difficult, the chief requirements are care and time, and the best results are always gotten by giving time to the work and not trying to do it in a rush. As with any other art or craft, one needs to study the medium before using it and another fact that has only been too often forgotten, is, that batik has design and knowledge of colour as its foundation and I would like to advise readers who have not studied these essentials, to leave batik alone until they have acquired some understanding of them. 
Most of the hints given here are the outcome of the many years that I have spent making batiks. Having seen it done in Java as well as in Holland, I have had an opportunity to compare the different ways of working, and by experimenting, have found many little helpful things which I gladly share with present and future workers.

In the last few years, batik has advanced in this country with rapid strides and I am sure that a good deal of this is the result of the interest which manufacturers, especially those in the silk industry, have taken in its development. Batik work, however, is not a manufacturing process. The moment we try to commercialize it, that is, to make the same design in quantities, the quality decreases; a great deal of the beauty of a batik lies in the personal touch of the artist or craftsman who makes it, and we may safely say that neither of them is able to do machine work and produce a practically unlimited quantity in a short time. It certainly is a pity that some manufacturers have already tried to commercialize it by means of using untrained boys 
and girls to execute in quantities the designs of others. When one sees the result of these efforts, one is inclined to ask, "Is it a good idea to spread the knowledge of batik?",

On the other hand, if the buying public knows more about the work than it does now, if they know the time and the care it takes to make a good batik, then I am sure that their desire for good batik will increase and the manufactured product soon will be where the other manufactured arts have gone.

Before going on to the description of batik, I should like to say a word of thanks to Olive Earle, for valuable help. Also to "House and Garden" and "Elsevier's Geill : Maandschrift" for their kindness in lending me some of the photographs used.

New York, April, 1919.

Pieter Mijer. 


\section{CONTENTS}

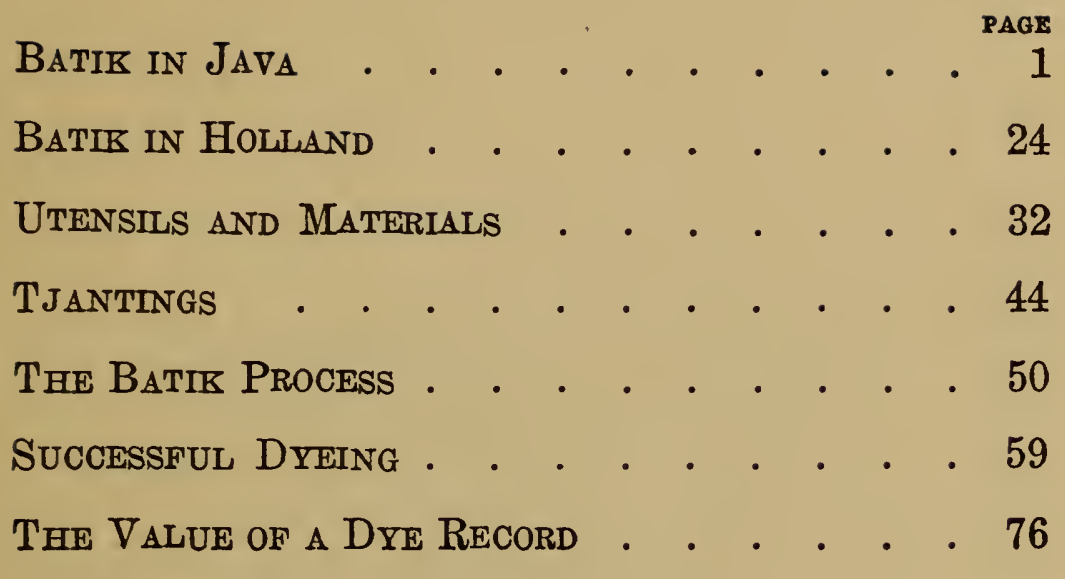





\section{ILLUSTRATIONS}

Chinese Screen Panel by Pieter Mijer and Emile Weeckers . . . . . . . Frontispiece FACING

Javanese Kain Kapala . . . . . . . . 2

Enlarged Detail of Native Sarong . . . . . 4

Native Design Showing European Influence . . 14

Pure Native Design Adapted for European Use . 14

Conventional Fish Design by Chris Lebeau . . 26

Geometrical Fish Design by Chris Lebeau . . 28

Stork Panel by Chris Lebeau . . . . . . 30

Flamingo Curtain by Pieter Mijer . . . . 30

The Use of Batik in Interior Decoration . . . 32

Dyeing of Textile . . . . . . . . . . . 34

Cleaning the Tjanting . . . . . . . . 34

Floral Design Entirely Executed with a Brush . 36

Various Types of Tjantings . . . . . . . 46

Scarf Batiked by Hazel Burnham Slaughter . . 50

The Right Way to Hold the Tjanting . . . . 54

The Use of the Brush for Filling Spaces . . . 54

Tank for Separating Wax from Gasoline . . . 58

"Spring" by C. Bertram Hartman and Pieter

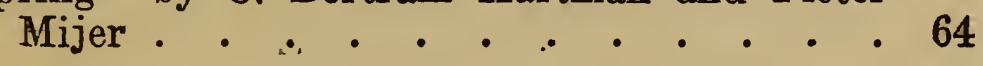




\section{ILLUSTRATIONS}

By following the arrows in the above chart it will

FACING easily be seen which colours should be mixed together in order to produce a given colour and the various lengths of the connecting lines indicate about the proportion in which the dyes should be used . . . . . . 68

Successive Stages in the Making of a Batik . . 74

Successive Stages in the Making of a Batik . . 76

The Use of Batik for Costume . . . . . 78

Sorceress by Arthur Crisp and Pieter Mijer . . 80 


\section{BATIKS, AND \\ HOW TO MAKE THEM}





\section{BATIKS, AND HOW TO MAKE THEM}

\section{BATIK IN JAVA}

INVESTIGATION shows that there never was a time when the art of batik did not flourish in Java. The robes of idols worshipped in prehistoric days were decorated very much in the same way as those of today, and apparently the modern native method of doing the work differs little from that employed so many hundreds of years ago. The literal translation from a Javanese paper on the batik art, which concludes this chapter, shows something of the confusingly elaborate process used in the East, while the description of the modern American way of working explains how comparatively simply, effective and beautiful results can be obtained.

The chief difference between the occidental 
DIFFERENCE IN METHODS and the native way of batiking is, that the occi. dental starts his dyeing with the lightest colour and dyes his tones over each other, whilst the native dips his fabric in the darkest colour first and removes the wax each time that he needs a lighter shade and he only uses dyes that set by oxidation. Of course their batiks have to stand very much rougher treatment than the textiles decorated here and to make the dyes stand the terrific glare of the sun, the innumerable washings, and the regular dips taken by their wearers who are tremendously fond of bathing, it is necessary for them to take every precaution to produce fast colours. Their methods may seem complicated, but it would not be amiss if American batikers were to use a little more of the patience and craft that the native exercises, instead of eternally seeking short cuts to superficially beautiful effects.

Batiks are chiefly used in Java for wearing apparel and as a rule are made of calico which is imported from Holland and England, although homespun cotton is occasionally found and was used, of course, before trading with 


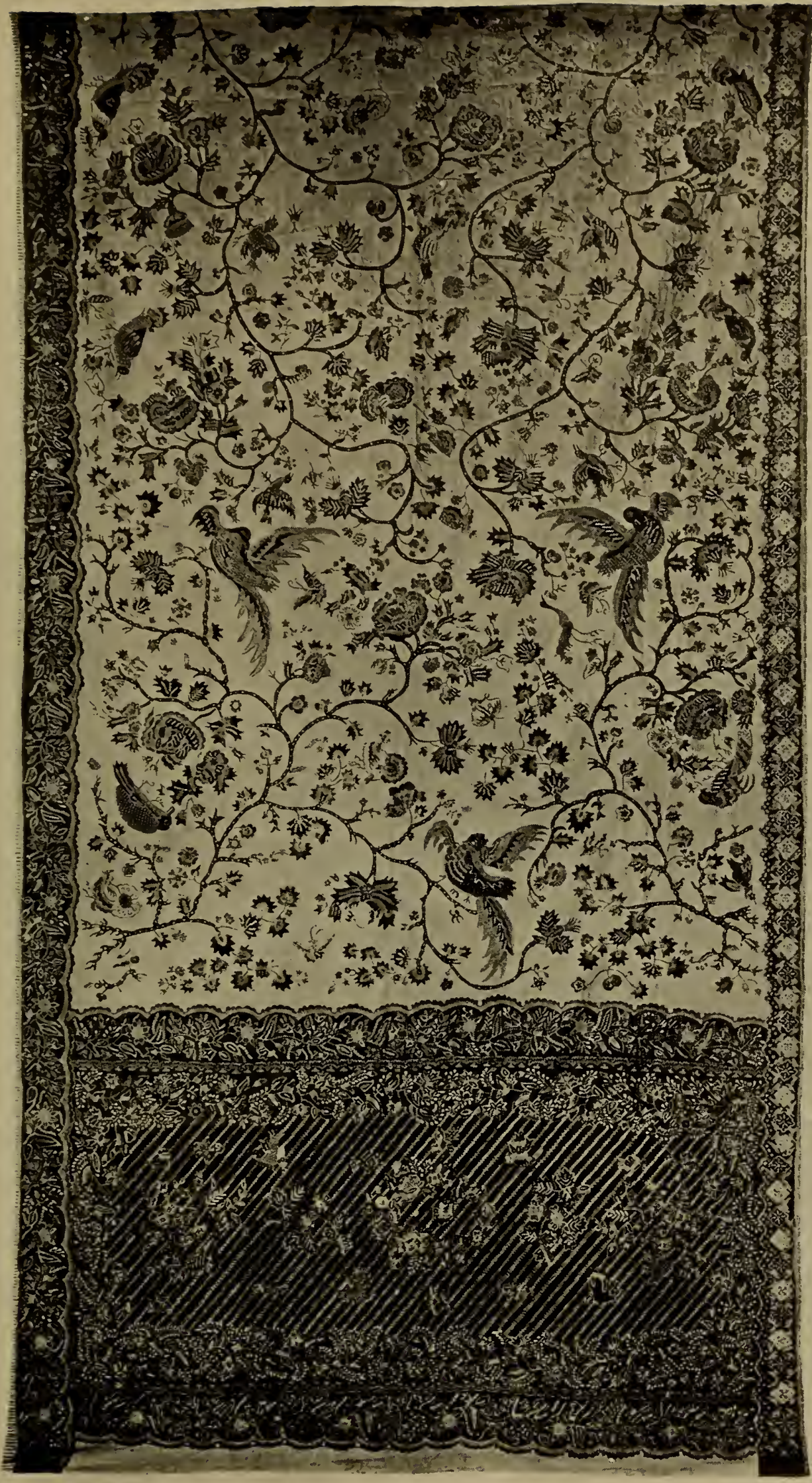



Europe developed almost "Mail Order" facilities.

The costume is similar for men and women JAVANESE and consists of the "sarong," the "slendang" Costump and the "sarong kapala." There are two types of sarong or loin-cloth worn, which are known as the "kain pandjang" and the "kain ratss kapala"; the former is decorated with an allover pattern and is used for "every-day" wear, whilst the "kain kapala" is a more expensive form, which besides the all-over pattern, has at one end, from selvedge to selvedge, an elaborate design. There is no intricacy of cutting in a sarong as it consists merely of a piece of material from three to four-and-a-half yards long and about forty-two inches wide. The material used for this garment is almost always cotton of varying grades.

The Javanese sarong facing page 2 is made in four colours, the cream colour of the original material, a bright indigo blue, red, and purple which is the combination of the red and blue. The main part of the sarong is decorated with a flower and bird all-over design, the ground 
being the cream colour of the material, while the red dominates in the flowers and birds. The wide border has a red background with a cream floral decoration, and the narrow border has a blue background with an ornamental design in cream and red. The kapale of this sarong is in red, with a scattered floral decoration and filled in with a characteristic Javanese filling-in pattern. The purple notes are scattered through the design. Facing page 4 is shown an enlarged detail of this design.

SLENDANG The "slendang" is no more complicated as to shape and the decoration is either in the form of an all-over design, or it has a plain centre with a decorative border. It is usually about three yards long and eighteen inches wide, and it is worn by the women who throw it over their heads, scarf-wise, but its use is more general as a "carry-all" for babies and other personal effects.

HEAD-DBESS The "sarong kapala" is a square piece of material worn chiefly by the men and is wound around the head in a kind of turban shape. After it has been folded on the head to the satis- 


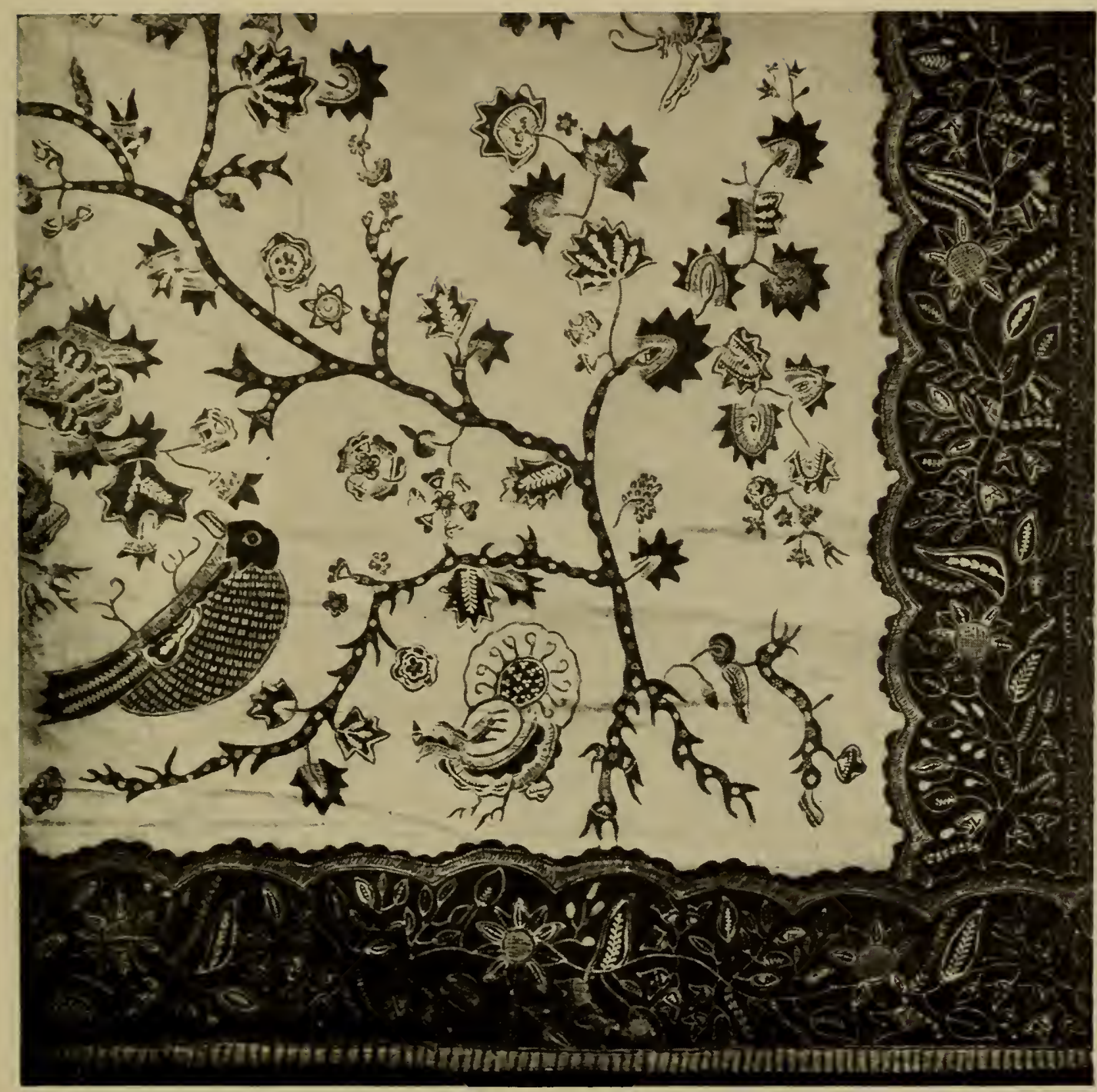

ENLARGED DETAIL OF NATIVE SARONG 

faction of the wearer, it is taken off very carefully and starched on the inside.

The women sometimes add an upper garment, called a "kemban"; this is just a long straight strip which is wound tightly round the body. The shoulders and arms are left bare, for they are great workers and do not allow their movements to be hampered by an undue amount of clothing.

The designing and waxing of batiks is done largely by the women whilst the men usually JAVANESE take care of the dyeing part of the process. The designs, whilst apparently originating with each individual worker are founded as a rule on what one might call standard designs; these have been used for generations, although in course of time they have changed in character somewhat. In most cases, any one familiar with these Javanese classics can trace the modern designs to their source and will recognize in present-day interpretations, figures wellknown in native folk-lore.

Other designs have significance in that they 'designate rank or social prestige. Some hun- 


\section{BATIKS, AND HOW TO MAKE THEM}

dred of these patterns have regular names, such as "batik parang rusa" and "batik sawat"; these two are reserved for the exclusive use of royalty, and many designs are esteemed as much for their social ranking as for their artistic merit. Decorated silk is occasionally worn by the native aristocracy; it is not in general use, however, and is always made in the form of a "slendang" and worn as a scarf. The colours found in a batik can be interpreted to denote the part of Java in which it was made. Those from Djocdja and Solo are executed in rich tans, beautiful golden browns and deep indigo blue, which colours are used on the royal batiks; the work from these districts is sombre in tone but very rich in design. Pekalongan batiks are usually in white and different shades of blue, or rather cream and blue, for the native treats his fabric with oil before starting to work and this gives a rich creamy tone to the white. Dead white itself is never used as it is literally associated with the dead, being the colour of grave cloths and always signifying death. Variety of colouring in a batik will 
mean as a rule that the piece had its origin in the district of Samarang.

The prices of the garments of course vary, according to the amount of work on the piece. "Kains" can be bought as cheaply as a dollar each and sometimes as much as $\$ 25.00$ is paid; however, a batik costing as much is rare, and is usually one made to special order. About two to two-and-a-half dollars is the average price one would have to pay for a garment in Java.

Besides the batik done entirely by hand, the TJAPS native produces a decorated material known as "tjap." This method can best be compared to block printing, the wax being printed on to the material instead of being applied with a tjanting. Instead of the wooden block associated with block printing, the native uses a sort of die made of wood, on which the design is made by the insertion, edgewise, of thin strips of brass or red copper; in some cases the whole die is made of the red copper. These "tjaps" are reminiscent of the work done in Madras where a similar process has been employed 
since the 15th century, for the direct application of the dyes.

Some "tjaps" are done entirely by printing with blocks, while others are partly hand work. The dies are used as time savers when making borders or patterns with a regular repeat. The native artists consider these substitutes, which are sold to the poorer classes for daily wear, very inferior to real batik and no Javanese of any standing would dream of " lowering himself " by wearing one.

At the present time not many die-makers are found, as there is only a comparatively small market for the work. A die is so solidly constructed and lasts so long, that once made, there is seldom a re-order of the same design. The price of dies varies according to the size and elaborateness of the design, ranging from about 25 cents, American money, to as high as $\$ 24.00$. In Samarang there are still a few men who trade in these tjaps, whilst in Soerabaja there is only one man known who is able to make them.

The copper used in the making of tjaps comes 
in three different weights; the lightest is used for the making of fine outlines, the second weight for the heavier lines, whilst the third and heaviest weight is used for the frame work. Like the tjanting, the tjap is-constructed in three parts; first, the body of the instrument which is composed of the variously bent strips of copper which make tie design, then the frame-work which holds these strips together and lastly the metal handle.

The tjap has to re-place the work done with the tjanting, therefore the object of the tjapmaker is to re-place all tjanting lines with strips of copper of varying sizes, which, when printed, will give the effect of perfect tjanting work. To that end, the strips of copper have to be curved and bent, and are set in a vertical position, that is, with the edges uppermost; this of course is very delicate work which requires good craftsmanship and much patience.

In making the tjaps, the copper plates of different thicknesses are first cut into strips, each strip of the same width. The design for the tjap is made on paper, and the copper strips 
are bent in the various shapes as indicated in this design. Here is where the good craftsmanship is essential as it is no easy matter to reproduce fine curved lines with the strips, especially in the case of flowered designs as no sharp angles may be shown in the bending of the copper. Then the whole design is soldered together, and fixed by the same process on to the frame to which the handle is attached.

This does not, however, complete the diemaker's work, for as in batik work with the tjanting where the material is waxed on both sides, so with the tjap does the fabric have to be printed on the reverse side as well. Thus, the die-maker has to make a second tjap in which the design is the exact reverse of the first one. It takes a die-maker about twenty days to make a complete set, that is two corresponding tjaps, each about eight by eight inches square, for which he gets about $\$ 8.00$. Out of this of course he has to pay for his materials.

When the tjaps are finished and found correct, that is, when every little line on one die 
is found to correspond exactly with the same line on the reverse block, then it is the business of the printer to print the tjaps so that no difference is shown in the design. The making of a pair of tjaps is only necessary when an irregular design is to be produced, as in the case of a symmetrical pattern the same die can be used on both sides.

For the reproduction of a not very elaborate tjanting design, a set of thirteen to fifteen tjaps is required; this means with the reverse set at least twenty-six to thirty separate dies. The original outlay for the making of a tjap may be great, but if the amount of work that can be done with one set is considered, it can be seen at once that the prices of pieces done by this process will be very low.

The printing of tjaps is practically always done by men. The workman sits on a low stool, and in front of him is a slanting table to which a large pad is attached; over this the piece that is to be printed is spread. The wax is heated in a flat pan, in which there is a pad of jute, covered with unbleached muslin. The wax is 
transferred to the metal by pressing the tjap on to this pad. To remove the surplus wax from the tjap the printer swings the die up and down a couple of times and then presses the tjap on to the material in the place where the decoration is desired. After covering one side of the material in this manner, the same process is repeated on the other side. As the wax shines through the fabric, it is not a difficult matter for the printer to place his die in the exact position, so that it will register correctly, but nevertheless, there will be very few pieces made in this way found without a slight inaccuracy in the design. Although all the actual line work in a tjap is done by the use of dies, a certain amount of the work, such as filling in spaces and big surfaces, has to be done by hand with the tjanting. This, however, amounts to a very small proportion of the work when compared with the amount of labour required in the making of a real batik. A good printer can print about twenty pieces of material, sarong length, a day, while it would take twelve to fif- 
teen days to produce one piece of a similar design, with a tjanting.

The European printed imitations of batik meet with very little favour among the native Javanese, who are very critical of art and craftsmanship and the importations only find a market among the poor.

For the most part, batik is a home occupa- NaTrVE tion of the native, but some districts have be- INDUSTRY come quite manufacturing centres. The industry is chiefly under the management of the Chinese with the natives as their workmen. In the district of Lassem, where a great deal of batik work is done, the Chinese employers give the work out to the natives, who do it in their homes. Fifty to a hundred kains will be given out to one man, who will have them waxed and they will thea be fetched by another worker who will do the dyeing. This work will bring in to the native, on an average, the lordly sum of two and a half cents (American money) a day, and it is estimated that in the neighbourhood of Lassem alone, there are some 4300 peo- 
14 BATIKS, AND HOW TO MAKE THEM

ple subsisting on this munificent salary. At that, this group of workers are rather better off than the women who are employed directly by the Chinese for the finer batik work. Large numbers of them bind themselves to work for three years, at the beginning of which period they are given thirty gilders, equivalent to about $\$ 12.00$; they are given board and lodging and once a year a new outfit, but they receive no more pay. Many of them work like this for years in succession and from time to time they borrow small sums of money from their employers which they cannot pay back, with the result that they are never out of debt and are consequently, to all intents and purposes, practically owned by their exploiters. Authentic figures give 2100 natives working under these conditions in Lassem.

There are a few establishments run by the Dutch in Java, who, besides producing pure native designs, have used native adaptations of European designs with splendid results.

A combination of Javanese and European influences is shown in the illustration facing page 


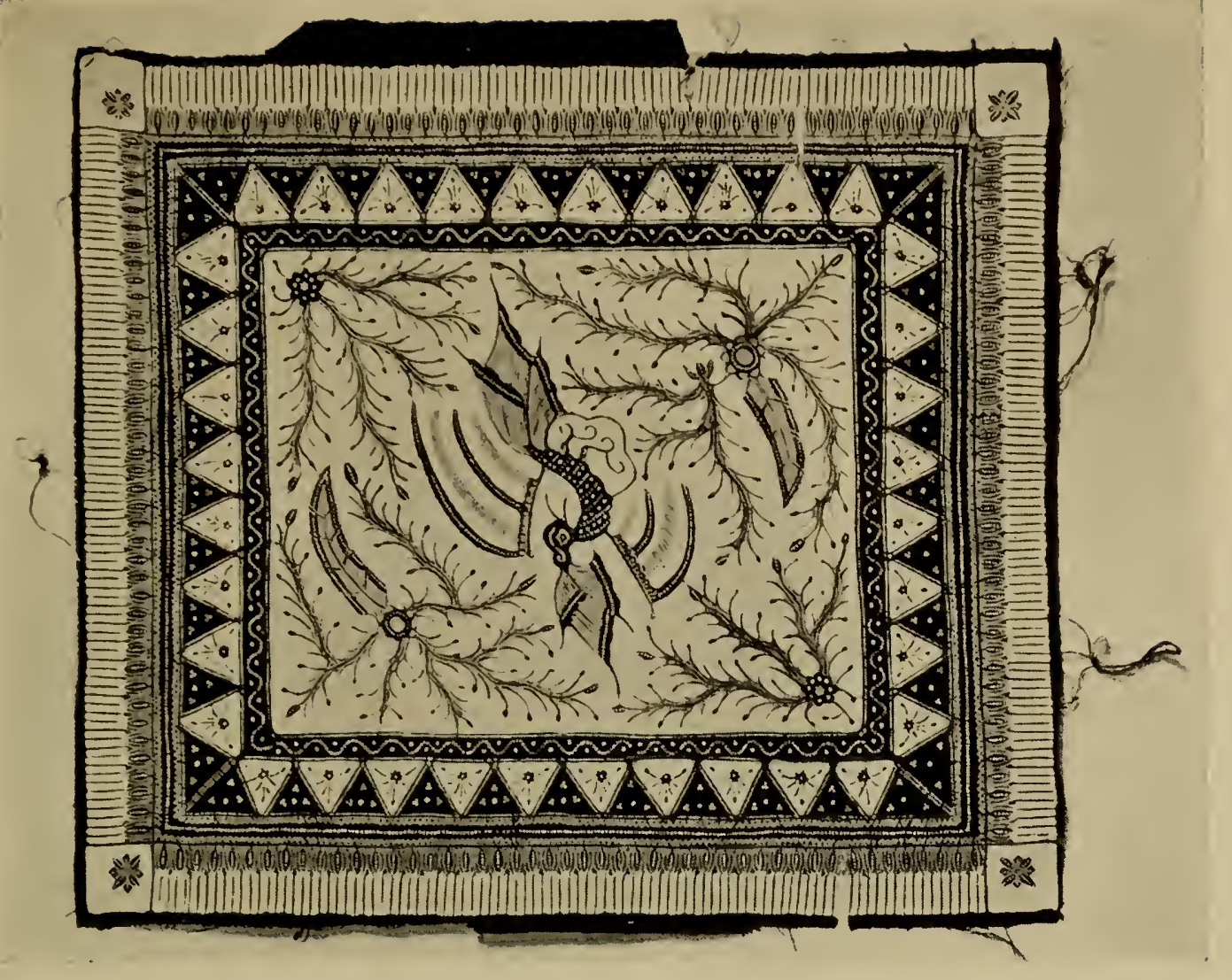

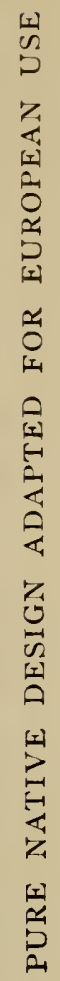

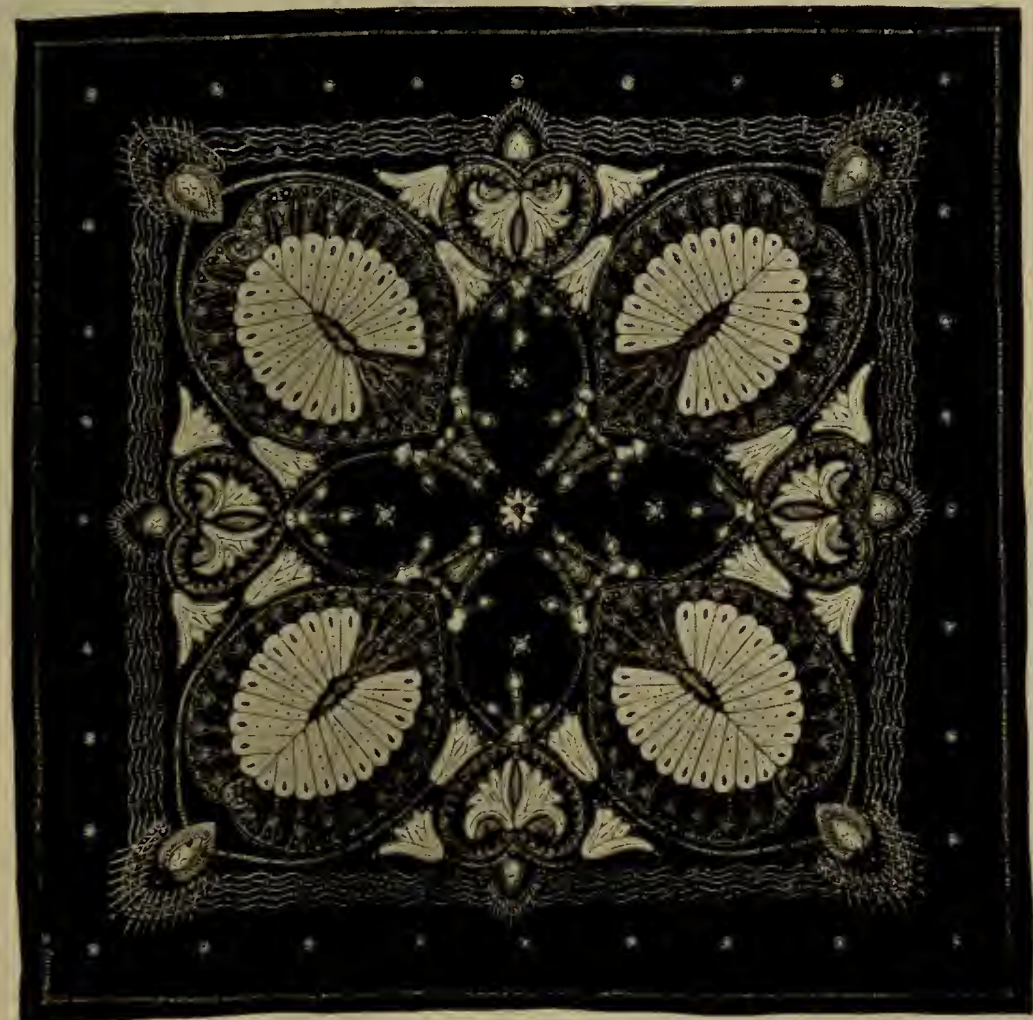

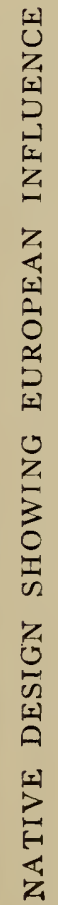



14. This pillow-top, batiked by a Dutch artist, has native motives, arranged in a symmetrical design. As a batik, it is about the finest piece the writer has been able to find, as there is no flaw in the execution. The stiff geometrical pattern, however, does not give quite such a pleasing effect as the freer Javanese design. A sample of this is shown facing page 14 which is pure Javanese decoration. It shows the arrangement of a bird and some octopuses and was used for a small pillow-top; the artist has been left free in this design, not being tied down to a geometrical repeat, and the result artistically is far superior to the previous design.

In the event of some enthusiast wishing to batik in the actual native manner, he can do so by following the process as described by a native and translated here word for word:-

"Batik is the art of dyeing fabric in one piece NaTrve in different dyes consecutively, through the PROCESs combination of which the pattern of the design is produced. The materials used in this process are cotton and very occasionally silk, wax, wax mixed with rosin and dyes. The dyes usually 
are vegetable although aniline is used, but rarely.

"The first of these batik requirements the native buys at the Pasar (market), the dyes they make themselves and in the case of the blue dye it is as a rule the property of a professional dyer, who is called the 'toekang medel.'

"The cotton used now by batikers is always of European manufacture and is graded according to the fineness of the texture. The different qualities are known severally as, 'mori moeslim' or fine-weave cotton, 'mori mentah' or unbleached cotton, and 'mori kasar' or coarse-weave cotton. The second grade is subdivided into 'mori mentah aloes'. which is the Ine grade of the unbleached cotton and 'mori mentah kasar' or coarse unbleached. This last kind is only used by the native aristocracy for the clothing of the members of their houshold; they themselves wear batik of 'mori moeslim' or 'mori mentah aloes.'

"The measure used when cotton is bought at the 'Pasar' is called 'katja' or 'saptangnan' and it is a square measure, that is to say, 
if, for instance, the cloth is a yard wide then the measure or 'katja' is a yard square and if the width is a yard and a half, the 'katja' is a yard and a half.

"The cotton as it comes from the market is not immediately ready to be batiked. If it is a bleached cotton it has to be treated for the removal of all the starch, chalk and other stiffening with which it is dressed. This is done by washing it several times in clear cold water. It is then soaked for several days in cocoanut oil; this in its turn is boiled out in water containing the ashes of burnt rice stalks; this process is continued till the fabric is free from oil. This soaking and boiling is always done, whether the material is bleached or unbleached, and is called 'mateng' which literally translated means 'done' or cooked thoroughly.

"After the piece is dried in the sun, the cut edges are hemmed-'didjilid.' Now the material has to be starched again, 'njekoeli'; this stiffening is to prevent the wax from flowing too freely,- - a condition known as 'mresep.' The rice water that is used for this, is made 
from a strained rice gruel, or more simply, the water is used in which the rice has been boiled. After the material has been starched it is 'dipe' or dried once more in the sun and it is then rolled up. This roll is laid on a wooden board, 'kemplomgen' and pounded with a wooden hammer, 'gandeng,' or if a hammer is not available, the wooden rice pestle, 'aloe' can be used. This process is called 'nganplongi' and is to make the material soft and supple. Now the material is ready to be batiked, and the following materials and tools are needed.

"1. Wax. Usually six parts of 'melam geplak' and one part 'melam poetih' are used, with sometimes the addition of a little 'melam ireng.' The 'melam geplak' consists of a mixture of 'damar mata koetjing' which is a kind of rosin that comes from Borneo, melted with animal fat. The 'melam poetih' is pure bees-wax and the 'melam ireng' is dark coloured wax which has been used already in a previous batik and which has become dark from the blue dye which it took up when in the blue 
dye bath. The first two kinds of wax can be bought at any market, but not the 'melam ireng,' as every one who batiks always saves enough dark wax from former work, or in case of need, a neighbour will always lend some.

"2. A pan called 'wadjan' in which to melt the wax. This is generally of iron, though poor' people use stone pots.

"3. A little copper instrument called 'tjant- DIFFERENT ing' used in drawing with the wax on the material. It is made of fine thin red copper and KINDS OF TJANTINGS has one or more little spouts and a bamboo handle. These tjanting have different names according to the type of work for which they are used. (a) Tjanting 'isen isen'; this has a very slender spout and is used to make very fine lines and little dots. (b) Tjanting 'kjandangen': this instrument has a larger spout and is used to wax the parts which have to stay white in the first process. (c) Tjanting 'penangang'; this is the tjanting used to cover up the bigger surfaces. (d) The 'penembok' has a very wide spout to cover parts that are to be completely protected by wax. (e) The tjant- 
ing 'pengada' has two spouts next each other for the drawing of parallel lines. There are various other varieties that have three, five and sometimes as many as six spouts for making little rosettes and groups of dots. Tjantings are always made by men and the work is not subdivided, that is to say, one man makes the instrument from start to finish; as a rule the makers have at least twenty-five tjanting in the course of construction at the same time. It takes a good workman six to seven days to make about 250 of the little tools, that is, about forty a day. Figuring the cost of materials and charcoal used in the making, together with overhead expenses and the receipts figuring at the

PRICE OF NATIVE TJANTING rate of 24 cents (American money), for 240 tjantings, it will be seen that an excellent craftsman makes on an average about 30 cents in Dutch money, equivalent to 12 cents American, a day.

“4. The 'djegoel,' an instrument which replaces the brush used in Europe and is made of a thin wooden stick with a wad of cotton 
tied to the end. This is for waxing very large surfaces.

'5. The 'iroes.' This is a spoon made out of cocoanut shell and has a bamboo handle; it is used to mix the melted wax and to scoop the wax off the water in which the finished batik has been boiled.

"6. The 'wadja.' The copper pan in which the fabric is boiled when the wax is being removed.

"7. The "panjawanjan. A small movable stand over which the material is hung during the waxing process.

"8. The 'tjawang.' A small bamboo clip used to fasten the fabric to the stand. Rich batikers use an iron clip called "bandoel."

'9. The 'doelang.' A large wooden trough for dyeing.

'10. The 'pane.' A small vessel also used for dye made of wood, copper, or earthenware. '11. The 'blebeo.' A wooden straight-edge for use when drawing straight lines-a process called 'batikan garisan.' 
"12. The 'semprong.' A blow-pipe with which to blow the fire. The fire is made, as a rule, between three stones set in the form of a triangle, upon which the wax pot is placed.

"To do real batik work the proceedings are as follows. First the main out-line of the design is sketched on the material, with charcoal or pencil, and when this is completed the fabric is hung over the little stand and with the tjanting the design is drawn in with wax, the material meanwhile being supported with the left hand; the worker sits on a little mat in front of her stand. The finer parts of the pattern are drawn in without pencil guiding lines.

"When one side is decorated the piece is turned around and the back is very carefully drawn in. With all the surfaces covered which are not intended to be blue it is ready for the blue dye-bath. This dyeing in blue is done by the batiker herself or more often by the professional blue-dyer who does it for a small remuneration. If red is planned on the batik, the wax is removed from the places where this solour is wanted by sponging with hot water. 
The material is then re-starched with ricewater, aren sugar and pulverized randoe leaves, so that the wax will not run or become soft. The parts that are to remain blue have to be re-covered with wax and the piece is ready for the red dye.

"This red dye is made from an infusion of soga bark; successive dippings are made until the desired colour is obtained. To make the colour permanent and at the same time to obtain the much desired purple glow, the material is dipped in a bath made of a mixture of Java sugar, whiting, and alum. It is left in this solution for about an hour, after which it is well rinsed and transferred to a hot water bath. The water is boiled and the wax is dissolved; the wax floating on the top of the water is collected for further use. The finished batik is then dried in the sun. If other colours are required on the piece the same program is repeated." 


\section{BATIK IN HOLLAND}

BATIK in America is still a comparatively recent importation; brought here some ten years ago, it was met with absolute incomprehension and lack of interest, but its real merit as a means of decorating fabrics has earned it a place in the industrial art of the nation and year by year it is gaining wider recognition.

For two hundred and seventy odd years it has been known in Holland, to which country it was brought by the Dutch traders from Java in the middle of the seventeenth century. It was not, however, received very enthusiastically and the commercial failure that followed the importation of some 2000 pieces (which were finally sold at auction, as no market could be found for them through regular channels) did not encourage traders in their efforts to popularize batiks. From that time, that is, about 1750 until 1817, interest in the work decidedly flagged and the honour of reviving it 
must be given primarily to Raffles who gave a description of it in his well known "History of Java" published at the latter date. He, however, seems to have had very little personal feeling for the art and merely wrote it up as a matter of history, and it remained for the modern artists to give it is first real impetus.

The present keen interest in the craft is mainly due to Chris Lebeau, Dijesselhof and Lion Cachet, who have, by their wonderful DUTCH ARTISTS OF FAME work, revived and stimulated a nation-wide appreciation of the art.

American batik has recently gone through a phase of development similar to that experienced in Holland some twelve years ago. It has been in danger of getting into the class of transient "cults" and becoming a fashionable pastime with a rise and fall similar to the craze for doing peasart wood-carving, burnt-wood work or sweater knitting. But here, too, its real merit has saved it from becoming just a modish amusement. In Holland it was even introduced into girls' schools as a regular course, so that graduates might enter the social 
world fully equipped! Luckily for its ultimate survival, however, it required so much technical knowledge that it was soon left to serious students, but the desire for the beautiful results obtained by the process was not relinquished so willingly and the result was that people tried to produce the effect without the work. This imitation was called a "secret process" and enjoyed considerable vogue.

The general public believed that this substitute was real batik, because the material had been dipped and some wax had been used, but any one who knew anything about the genuine process, was not fooled and recognized that stencils and various other fake methods had been utilized. The unlimited patience of the native worker was unknown, and unsung was the thoroughness of the painstaking craftsman. At this period the watch-word was "speed" and the results showed it.

The importance placed on the "crackle effect" is another parallel in the phases of development in Holland and America. Crackle certainly has its place in the beauty of batik, 


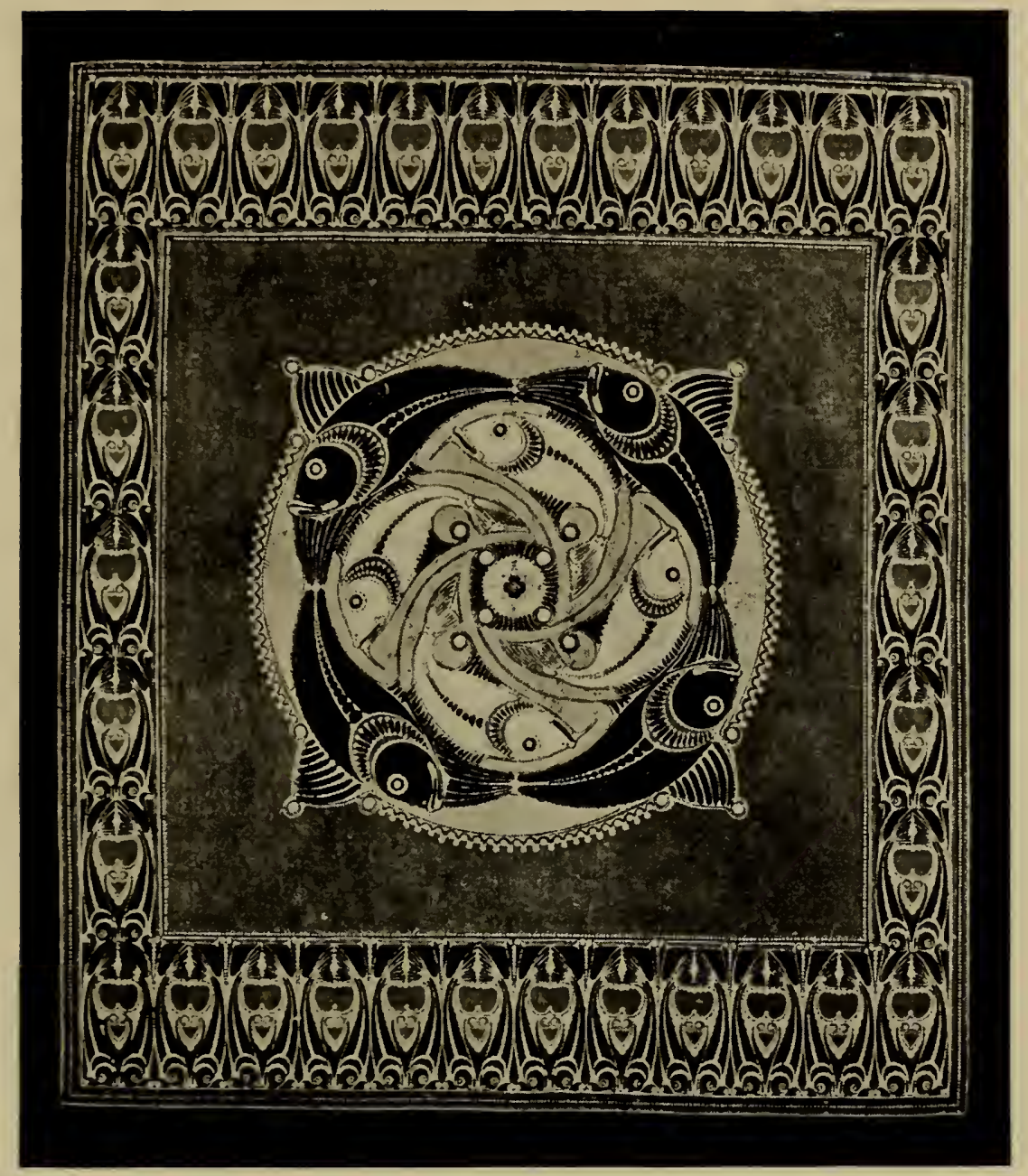

CONVENTIONAL FISH DESIGN BY CHRIS LEBEAU 

but the indiscriminate use of it as a complete motive of decoration in itself, is to be regretted. It would be used less, probably, if examples of the best native and European work were studied, in which real design and colour are the arresting features.

Even whilst admitting that the medium does limit the designer to a certain extent, study of the work of the before-mentioned Dutchmen, Dijesselhof and Lebeau, will show the variety of design, feeling and temperament that can be expressed through the batik process.

Dijesselhof considers batik a better way to DIJESSELHOF express himself for his mural decorations than either oil or water colour painting. He uses the brush to a great extent and works with great freedom of execution, making the medium conform to his own particular type of work. Le- LEBEAU beau, on the other hand, after the manner of the Javanese, sees the tjanting as the only tool with which to produce his richly fantastic designs. Lebeau is technically the greater artist and possesses a supreme disregard of time when he is producing a magnificently ornamented tex- 
tile; his attitude toward his work is reminiscent of that of the monks who in bygone ages, spent years on the intricate and beautiful ornamentation of their laboriously hand-lettered books of devotion. They, too, had perfection of design and craftsmanship as their only standard.

These men have been an inspiration to Dutch artists, and the illustration of a batik by Chris Lebeau facing page 26 will give the reader a good idea of the high standard of proficiency this Dutch artist and craftsman has achieved. It will be seen that no actual lines were used in these designs; if a line effect was wanted it was made by a series of little round dots, almost equal in size, with the result that a soft pleasing line is obtained instead of a hard one.

By graduating the size of the dots, from small to large, an effect is produced that never could be obtained with lines; not only are the lines treated in this way, but whole surfaces in which a light tone is desired, instead of being "covered off" with a brush, are laid in with countless dots very close together. As can be readily understood this hand-work requires the acme 


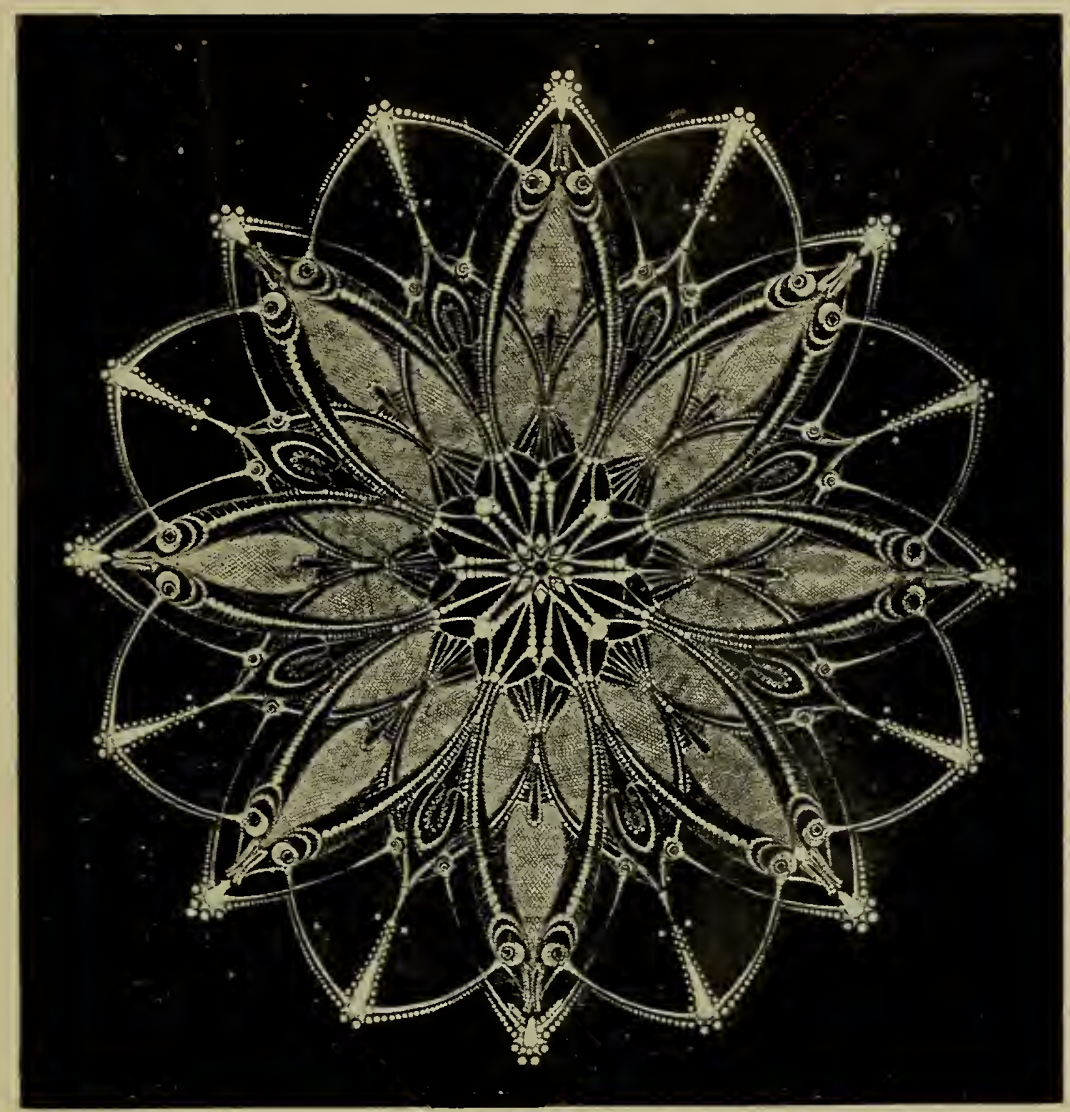

GEOMETRICAL FISH DESIGN BY CHRIS LEBEAU 

of craftsmanship, for if the dots are placed irregularly, that is to say, if their arrangement is not directly harmonious with the main lines of the design, the pattern formed by the spaces between them, would disturb the rest of the drawing.

In the second reproduction it can be seen that the little dots are actually laid in circles, but with such regularity that no circles are shown. The workmanship in the stork design is even more amazing than that of the two first decorations and it is hard to believe that a human being has had sufficient patience to execute such a design.

In Europe, batiks are chiefly used for in- EUROPEAN terior decoration; table covers, screens and lamp-shades being more popular than costumes USE OF BATIK decorated by the process. It is also used to a certain extent in book-binding, on paper and on parchment. Practically the same methods are employed when batiking these materials as for woven goods, but experimenters are advised to take the greatest care when handling paper, which of course. when wet, tears very easily. 
To batik parchment it is necessary, to first soak it, in order to make it pliable, then whilst wet, it should be stretched on a piece of plate glass, slightly larger than the parchment, and . glued at the edges with strips of paper binding. When thoroughly dry the design is pounced on or drawn in with pencil. Before starting to apply the wax the glass must be warmed from the back, in order to make certain of an easy flowing of the wax; if the parchment is cold it will be found that the wax congeals too quickly and will not be workable. The parts of the design to be left un-coloured are covered with wax as usual, and a little wall of clay is built around the edge of the glass; this forms a bath into which the dye is poured. The colour is allowed to soak in thoroughly and the dye is then poured off, the process being repeated if the tone from the first bath is not intense enough; other colours are applied in the same way. The wax is then removed by sponging carefully with gasoline.

Aniline dyes are used chiefly and occasionally acids which produce colour by their action on 


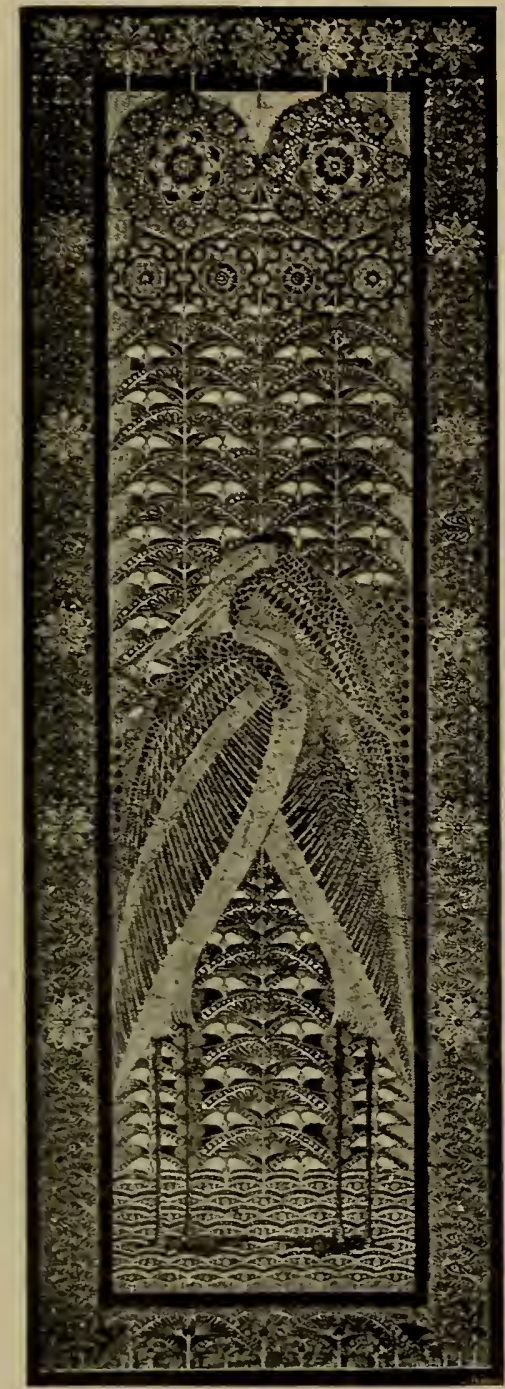

STORK PANEL BY CHRIS

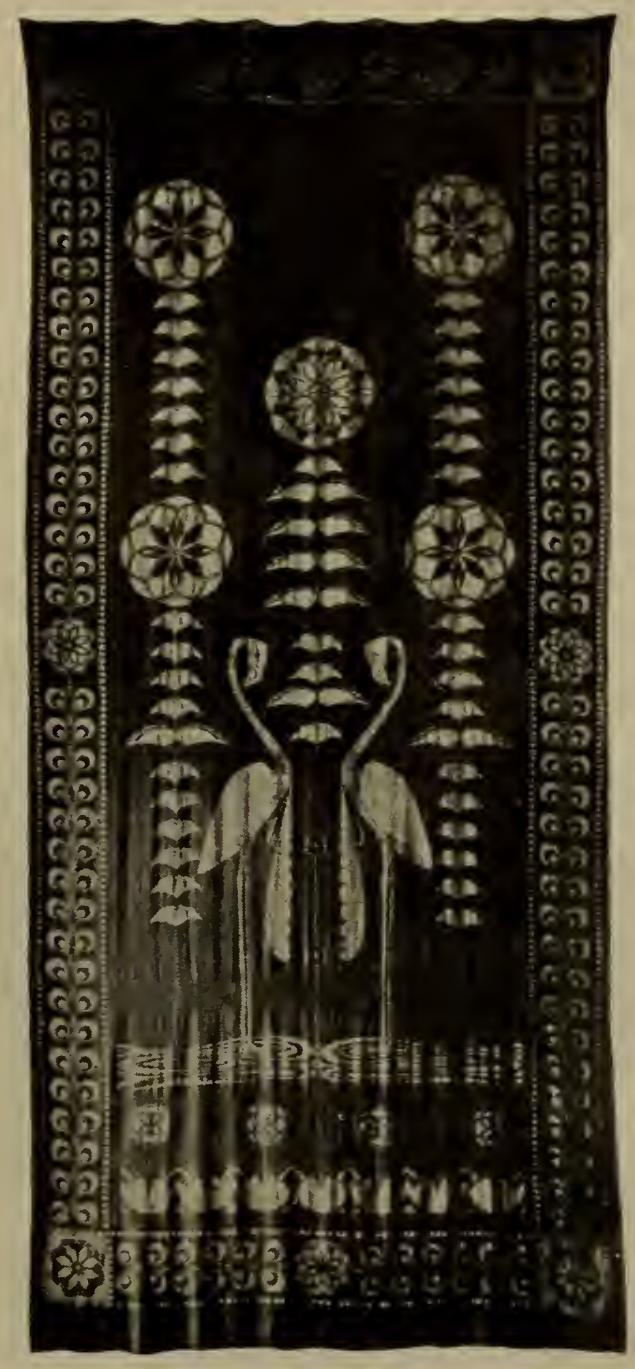

FLAMINGO CURTAIN BY
PIETER MIJER 

each other, are employed. Vegetable dyes are popular in Holland on account of their permanence, the Dutch being almost as particular about the durability of their work as the Javanese. This is natural when one remembers that, there, the batik art is considered in the same light as painting and sculpture, and frequent exhibitions are held for a public whose attitude toward the craft is very different to that of many Americans, who do not yet appreciate the art as an art.

Beside public interest, the government of Holland has done its best to stimulate the study of the craft. Experimenting stations are maintained, where free of all cost, the artist can have his batiked design dyed and he is given all the information and help that he wants. This, of course, means a great deal to the beginner who knows little or no chemistry, some knowledge of which is quite essential to one who would become a really expert dyer. 


\section{UTENSILS AND MATERIALS}

BeFore going into the details of the actual batik process it will perhaps be a good plan to give a description of the necessary tools and their management, wax, and various other essential requirements. The tools chiefly used, are the native instrument called the "tjanting," the brush, and the European wax pencil. Of these three the tjanting and the brush are most generally used, the wax pencil being a somewhat clumsy affair and hard to handle.

The "tjanting" used in America is a modification of the Javanese instrument; it is a little cup-shaped tool with a handle set at rightangles to the base on one side and on the other is a fine spout arrangement. Through this spout the hot wax is drawn by capillary attraction when the point is brought in contact with the material. In the best type of "tjanting" the spout is tapered toward the point; this shap- 

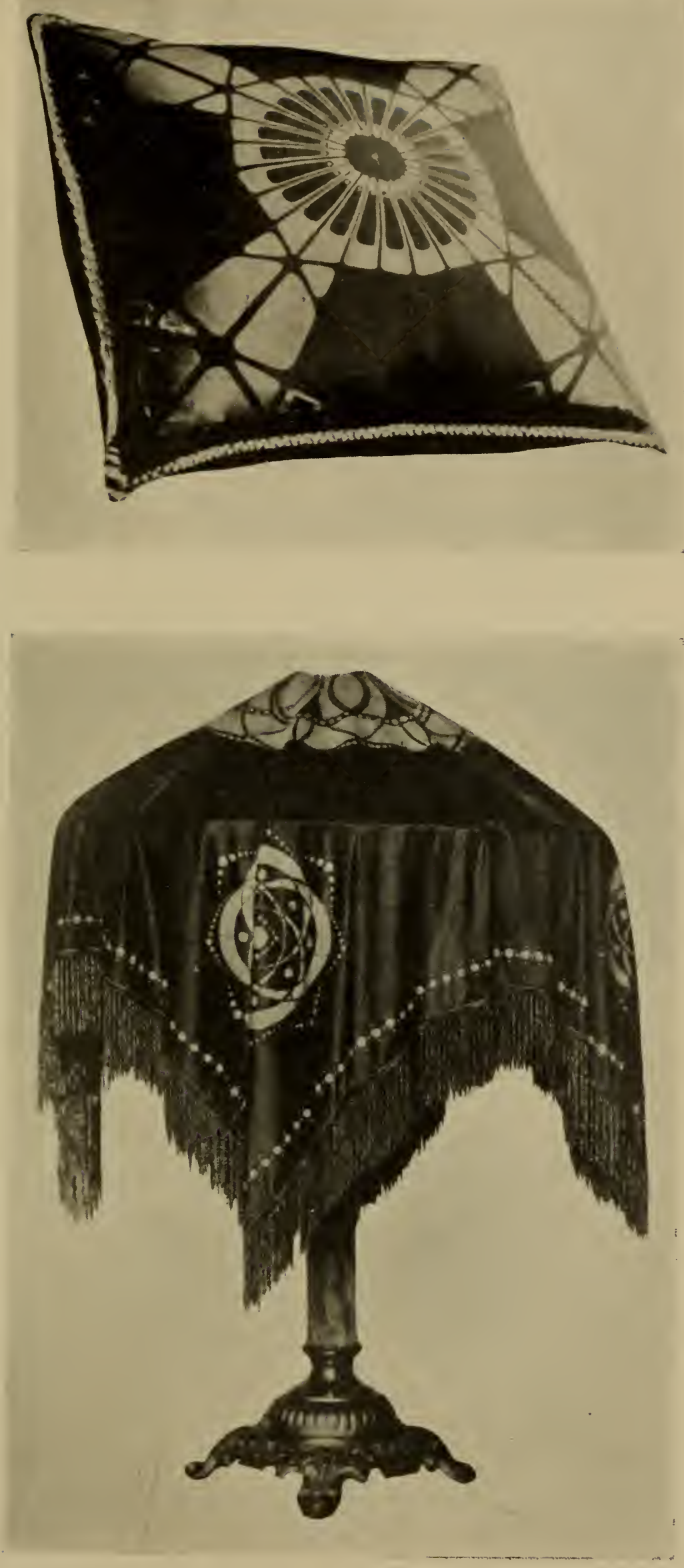

THE USE OF BATIK IN INTERIOR DECORATION 

ing is in order that the volume of wax, small though it is, will hold the heat longer than if the entire length of the tube were as minute as the hole through which it is finally drawn.

In batiking with the tjanting the wax is scooped out of the pot in which it is being kept hot and the instrument is wiped off carefully before it is brought near the fabric. It does not do to take a chance on having a drop of wax fall on the work as it is next to impossible to remove it entirely. Some people hold their tjanting directly over a flame to re-heat cooling wax, but it is a very unwise practice as there is a grave danger of hurting the spout and a likelihood of the wax becoming charred. If the wax does get too cold to work with, or the spout gets stopped up with chilled wax, hold the bowl of the tjanting in the hot wax in the melting pot and it will be found that the trouble is remedied instantly. If you have been unlucky enough to get grit or some other clogging substance in the spout, the insertion of a fine hair wire will usually clear it; this is almost a major operation though and should be performed most 
carefully as it is a delicate instrument you are handling and it costs money to repair it even if you are in the neighbourhood of some one who is able to re-solder it.

So fragile is the point of these fine instruments that even the sudden check caused by the rough fibre of some materials is sufficient to ruin the tip. When not in use the safest plan is to hang it in a box of its own or at least keep it in a place sacred to itself, with its spout upwards, so that there is no likelihood of accidental pressure to bend it out of shape. This careful handling of the tjanting is emphasized because, while the initial cost of a good instrument may seem high, it is a most satisfactory tool to use and with proper attention it should last a life-time. One that is in use today has been used steadily for the past twelve years and looks good for holding many more pints of melted wax.

The frontispiece shows a piece in which all the line work was done with a tjanting, the brush only being used to fill in the big surfaces, 


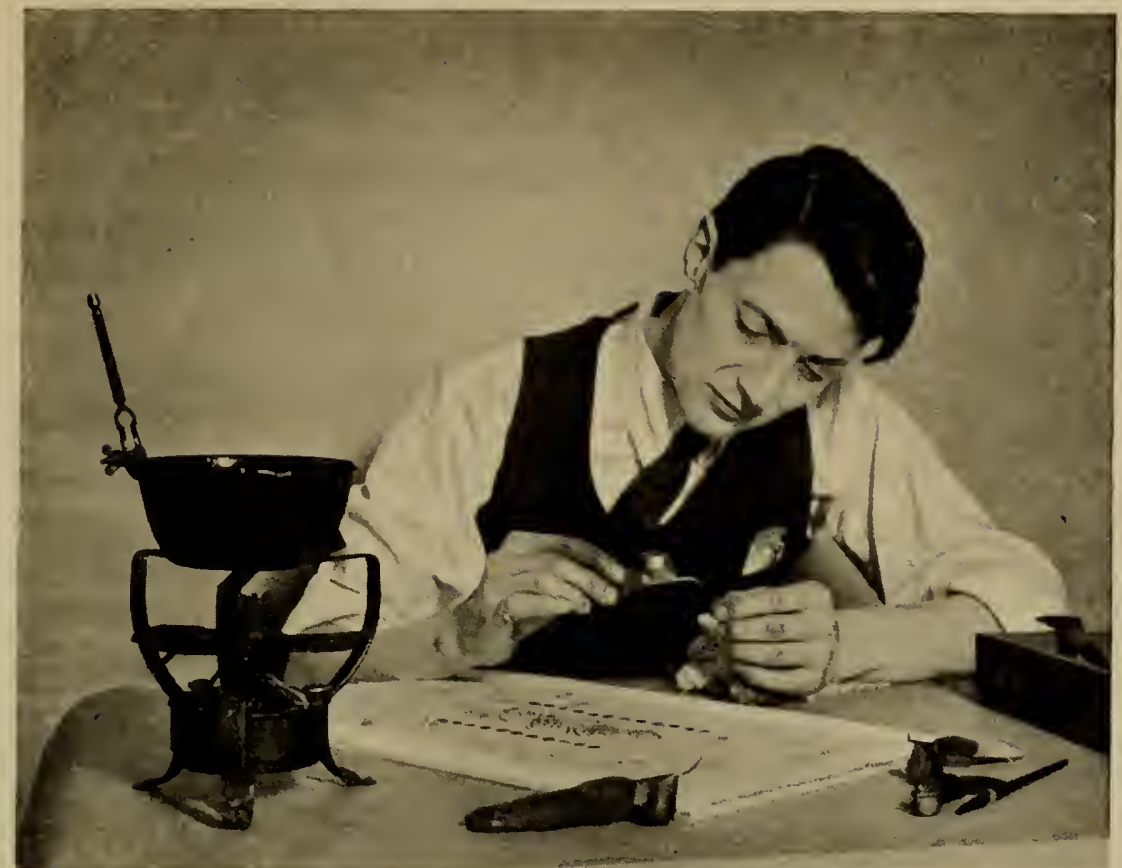

CLEANING THE TJANTING

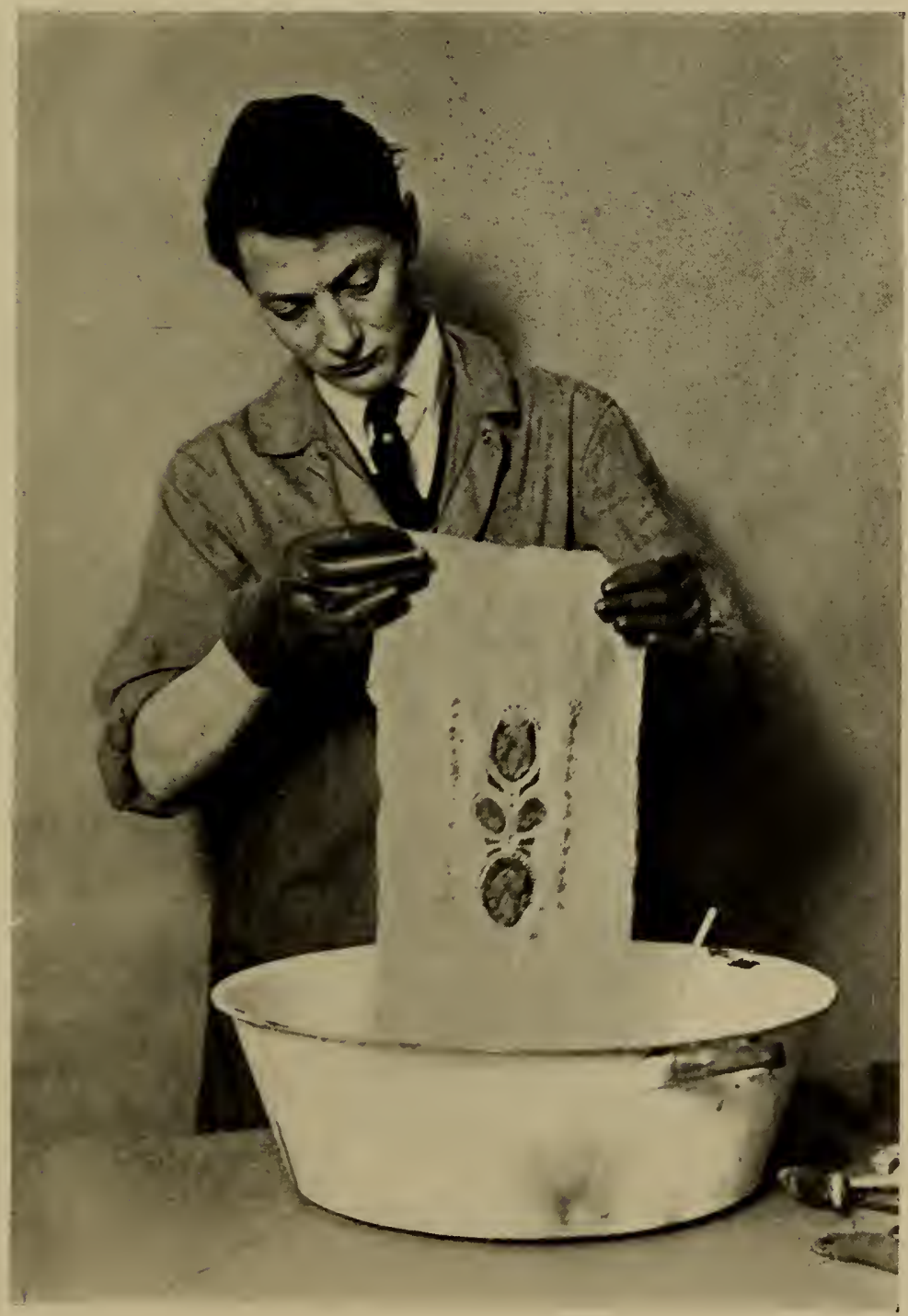

DYEING OF TEXTILE 

after the various dippings. The design is an adaptation from the Chinese, inspired by the decoration on a coramandel screen. The panel is worked out in seven colours: two golds, two greens, red, brown, and black. It was designed by the writer and executed by Emile Weeckers. and himself.

The spout openings come in various sizes and with the finest almost hair-lines can be produced. The wax when ready to flow forms an infinitesimal globule which will run freely when just touched to the material and skimmed as lightly as possible over the surface. A heavy hand will drop the point so that it touches the fabric; the moment it does this the hole is automatically sealed and the wax cannot flow.

Many batikers are not able to obtain a tjanting and would not if they could, preferring to do their waxing entirely with brushes. Brushes, properly trimmed and of various sizes, will certainly give very satisfactory results to the careful worker. Of course the minute line possible with the tjanting, is impossible to 
achieve with a brush, though a line as narrow as the sixteenth of an inch can be made by a practised craftsman.

USE OF BRUSH

PREPARING BRUSHES
The all-over floral design shown facing page 36, designed by the writer and executed by Miss E. Shirtleff, was made in six colours. This panel was done in the "blue group," explained in the chapter on dyeing. The outline of the flowers is in the original white of the material, the petals of the flowers range in colour from straw yellow to orange, with some of the outer ones in moss green. The background has a "wave design" worked out in all the different colours used in the flowers and an extra shade of dark green. The waxing of this piece was done entirely with the brush and has no line of a greater width than one-sixteenth of an inch. This fine work is easier with shaped brush; this shaping is done without much difficulty by dipping the brush, preferably a good sable one, into hot wax, and, without pressing the globule formation out of shape, gently wiping the excess of wax from the distended bristles. Allow this to cool and when hard, trim to a point with 


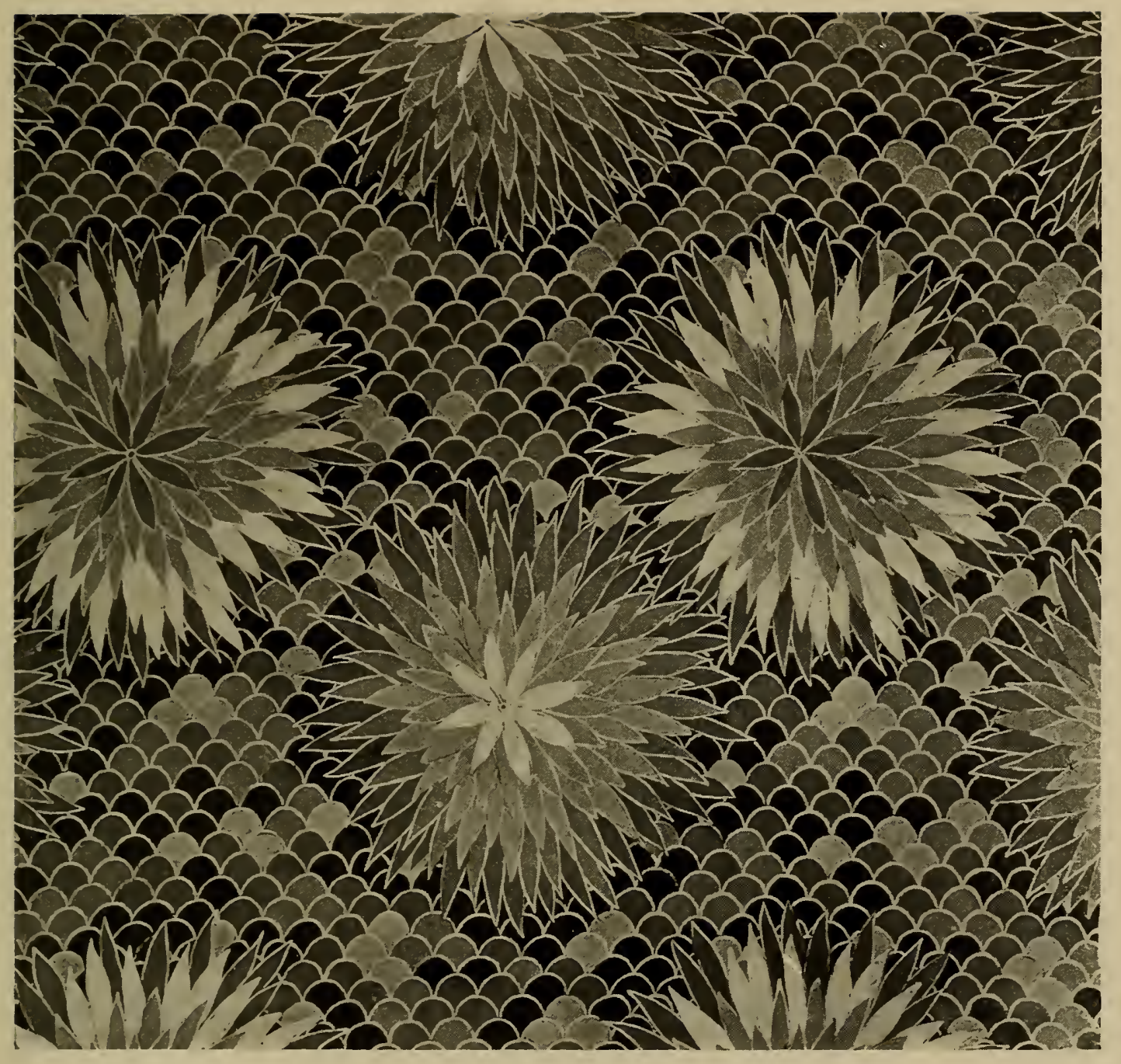

FLORAL DESIGN ENTIRELY EXECUTED WITH A BRUSH 

a sharp knife. Melt the cold wax out by dipping in the wax pot and you will have a brush that will be more manageable and will hold more wax for the size of its point, than one would have with the regular unshaped brush. For covering big surfaces, one or two flat soft-haired varnish brushes will be needed.

For waxing, bees-wax with a mixture of white WAX paraffin wax is used by most batikers, the proMIXTURES portion varying according to the brittleness desired. This of course is best worked out to suit the individual batiker's requirements and after a little experimenting one soon learns to get a satisfactory mixture. One part paraffin to five parts of bees-wax will give the consistency of medium to produce the crackle surface so popular with many artists in America. Pure bees-wax cracks very little and will stand the highest temperature when in the dye-bath, and inversely the larger proportion of paraffin used the more the medium will crackle and the cooler the dye-bath must be used if one does not want one's design to melt away. When no crackle "CRACKLE" at all is desired, the solution can be made more 
pliable by the addition of rosin. Use this, however, in hot dyes only, for it has unpleasant mannerisms, one of which is to increase the mixture's brittleness when it is made to undergo a cold plunge.

Whilst on the subject of wax, a word may be well said regarding the care that should be taken to keep water out of the neighbourhood of the wax pot. One has only to allow a drop of water to get itself into the melted wax just once, to find out what a horribly messy spattering and explosion can result. One may gain in understanding and be able to sympathize with long-suffering relatives who declare that "Batik is such a messy business," but it is hardly worth it. Of course it need not happen if a few precautions are taken, and it is perhaps better to take care at first than to run the risk of becoming unpopular in the household.

Another warning that may be of service to the worker in the country. Do not apply wax, in summer time, seated near an open window. A really true story tells how a batiker was sitting coolly working by a window and was vis- 
ited by a solitary bee, who took a good look and one sniff at the wax pot and flew away. $\mathrm{He}$ returned immediately, however, with all his relations who swarmed gaily all over the work, the wax-pot, and the worker to the great discomfort of the visited and the visitors. Exploding in boiling wax can hardly be a comfortable end to a busy life.

To complete the outfit one also needs a small agate pan in which to melt the wax, one about HEATING four inches deep will answer best and some sort of heating apparatus. A kerosenè stove should not be used unless one is willing to blacken one's utensils and most probably one's self. Gas or an alcohol lamp with an adjustable burner are more satisfactory than an electric attachment as the ability to regulate the heat makes for great comfort when one wants to keep the wax at an even temperature. Of course if necessity demands it, any heat producer available can be used; an electric flat-iron turned upsidedown can even be pressed into service although the inconvenience of having to keep one eye on the melting pot is great, when one wishes APPARATUS 
to give all one's attention to the design; but if it is not watched the result may be a most uncomfortable "smoking-out." Work in a warm room or near the stove and it will be found that the wax when in the tjanting will chill less quickly and will consequently be more manageable. These little hints may seem of small importance, but it is as well to take advantage of everything that will make the actual tool handling easier. There are likely to be troubles and mis-adventures enough with the rest of the process.

DYES

A great many people seem to be under the impression that the ordinary household dyes that are on the market are not good enough to use in batik work. There is a strong prejudice against Diamond dyes, but there is no reason for it, as these dyes when used according to directions, produce admirable results and are most practical for the beginner who is not in need of large quantities. For any one going extensively

REMOVING STAIN into dyeing, it is rather an expensive way of working and it is better to buy the dyes in bulk direct from the manufacturer. Rubber gloves 
will give some protection to the hands when handling materials in the dye-bath, but if, in spite of care, the hands or clothing become stained, soda or ammonia in the washing water will prove helpful. Lava soap is very good for removing stains from the skin.

One of the chief helps in successful dyeing is DYE TUBS a good vessel for use as a dye bath. If one is possibly obtainable, the best thing to use is a seamless copper tub. This utensil, however, is not within the reach of every student and it is quite possible to do satisfactory work in a good agate or enamel pan. Galvanized iron is safe to use with most dyes, but in time the acid used with some colours will eat into the metal. Be sure to get a big enough vessel as disaster follows goods that are crowded in the dye-bath.

A thermometer is quite a necessity, and one should also have a glass spoon and a stirring rod. For this latter, a couple of smooth round pieces of wood can successfully be substituted; these are used for lifting and manipulating the material in the dye-bath.

Batik can be done on all kinds of woven ma- FABRICS 
terial, such as cotton, silk, velvet, wool, mixed goods or leather. It is rather difficult to get satisfactory results on cotton owing to the fact that cotton dyes have to be boiled in order to attain any degree of brilliancy, and of course boiling is not practical when one is dealing with waxed material. Japanese habutai silk is perhaps the easiest fabric to use and best for beginners' experiments, as the wax penetrates easily and it takes colour well. This applies to chiffon and similar sheer materials, but of course their delicacy makes them harder to handle. Fibre silks, being composed of both animal and vegetable matter, should be dyed in "mixed goods dyes," or should be first dipped in a bath of cotton dye, and then immersed in a dye for silk, of a similar shade. Very heavy silks and velvets are magnificent when batiked, but they should be sent to the professional finishers to be treated when the piece is completed as it takes a great deal of effort and considerable skill on the part of the amateur to finish a large heavy silk panel or to raise the flattened pile of 
velvet. Taffeta silk and very heavy satin are not good fabrics for the batik process, owing to the loading used in their manufacture. 


\section{TJANTINGS}

EvER since the batik art has been practised by occidentals there has been a search for a tool to replace the tjanting, or perhaps not so much to replace, as to develop an improved edition. But after many trials, it seems that the tjanting in its original form, with just a slight variation in its handle, is after all, the best instrument for fine line and dot work.

The Dutch edition of the original Javanese tjanting is better than the native tool in two particulars. First, it is made out of heavier metal and is consequently much stronger and the second distinct improvement is the re-modelled handle which replaces the little tied-on bamboo affair. Of course when the difference in price is taken into consideration the Javanese tjanting stands away above any other,it costs from 1 to 10 cents in Dutch money, which is the equivalent of five tjantings for two cents, 
American money, whilst the Dutch-model tjanting made here in New York, is sold for from $\$ 5.00$ to $\$ 7.00$ apiece.

Various kinds of tjantings are shown in the accompanying illustrations. 1. The original Javanese tjanting. 2. The Dutch tjanting. 3 and 4. Belgian tjantings. 5. The Walther glass tjanting. 6. The wax pencil. The first two of these types have already been described.

3. A Belgian tjanting. This tool has a few very good points, but the trouble is, that whilst each factor in itself is good, the combination of them in the tjanting is not desirable. The cup of this instrument is made out of a brass ball out of which a segment is taken to form the top opening; on one side, not quite at the lowest point of the ball, the spout is placed, while the handle is fastened opposite to it on the other side. This placing of the spout has one great advantage as any impurity in the wax will settle below the spout opening, and clogging is less liable. The spout is made of solid brass plate; it is tapered and the nozzle has a fine opening. The only disadvantage to it is, that 
it cannot be shaped, that is, it cannot be bent up or down at the will of the worker.

The main objection to this tool is, however, that it is rather heavy by reason of its very solid cup and it does not balance well in the hand.

Besides the before-mentioned advantage of the spout being unlikely to clog, the greatest thing in its favour is, the long time that it holds the wax hot; on account of its round shape, the small opening on top, and above all, because of the thickness of the walls of the cup, the wax retains the heat longer than in any other tjanting made.

4. A second type of Belgian tjanting. This tool very much resembles some of the first tjantings made in this country. It is not very good, mainly on account of the spout, which is not tapered, and another weak point is the cup, which holds only a very little wax.

5. The Walther glass tjanting. This is a German invention and is certainly no improvement on any existing type of instrument. In fact it is a clumsy and awkward tool, difficult to han- 


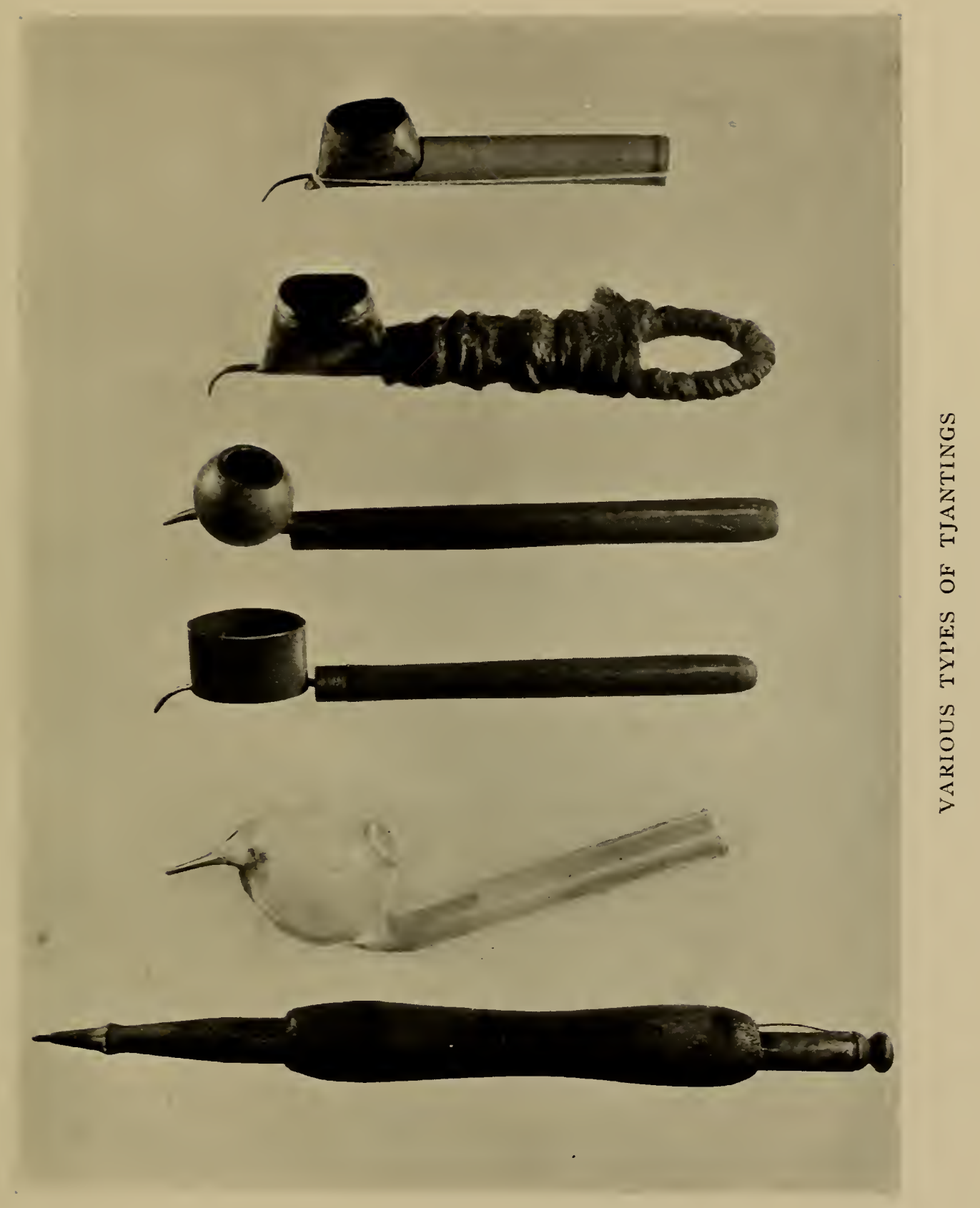



dle, and being made of glass it is of course, very fragile.

6. The wax-pencil. This is another German attempt to replace the tjanting and is made in two separate parts. First, the metal cylinder which holds the wax and replaces the cup and spout of the tjanting and the second part is the wooden holder, which slips over the cylinder and serves as a handle. The cylinder itself is of brass, shaped to a point at one end and at the other is closed with a brass stopper. The pointed end is fitted with a fine needle which is held in place by a minute spiral spring. This needle closes up the opening in the tube and prevents the molten wax from flowing out. When a flow of wax is desired, the pressure of the point of the "pencil" on the fabric, will push back the needle and release the wax.

To fill the tool, the wax is scraped into fine chips, or better still, cut into a thin bar, and inserted in the tube and closed in with the stopper. The wooden handle is then slipped back and the tool heated in a flame to melt the wax; when the instrument is sufficiently hot, the han- 
dle is slipped back in position, and work can be started.

A great draw-back to this tool is that it gets very hot, so hot in fact, that the wooden handle is likely to char, as is shown in the one illustrated, and after working some time one has to stop in order to give the handle a chance to cool.

Very fine work cannot be done with this instrument and the opinions as to its usefulness are very divided. Some people say the tool is as good as useless, whilst others cannot or will not work with anything else-this is most probably because they never had a good tjanting, if they had they would soon put their waxpencils in the discard.

The main thing in favour of the tool is, that it makes very little wax smoke in the room, but this is its only virtue and it does not have a monopoly of that, as any batiker, with a little care can keep his or her wax as hot as it is needed without having a column of smoke constantly coming out of the wax pot.

Although much time has been spent and trou- 
ble been taken in endeavours to supply a tool which would be better and more practical than the tjanting, it can be safely said that the original appliance has stood up successfully against all competitors and nothing better has yet been made. 


\section{THE BATIK PROCESS}

PREParation The first step in the batik process is to prepare OF MATERIAL the material. This is nothing more elaborate than a thorough washing, which will result in freeing the goods from any artificial loading and will shrink the piece and the size will not be an unpleasant surprise when the work is finished and one will not find that the triangle especially cut for a lamp-shade will not fit by an inch or so. If one is using "dyed in the piece goods" (that is, material already dyed one col, our when bought), it is a good plan to boil it for ten minutes, in order to remove any loose colour, and to make sure that no un-expected colour will run and mix itself with the dye in which the fabric is being dipped. The drying and ironing of the material makes it ready for the application of the design.

aPPLICATION Some people when making a simple design OF DESIGN draw directly on the material with wax, but it 


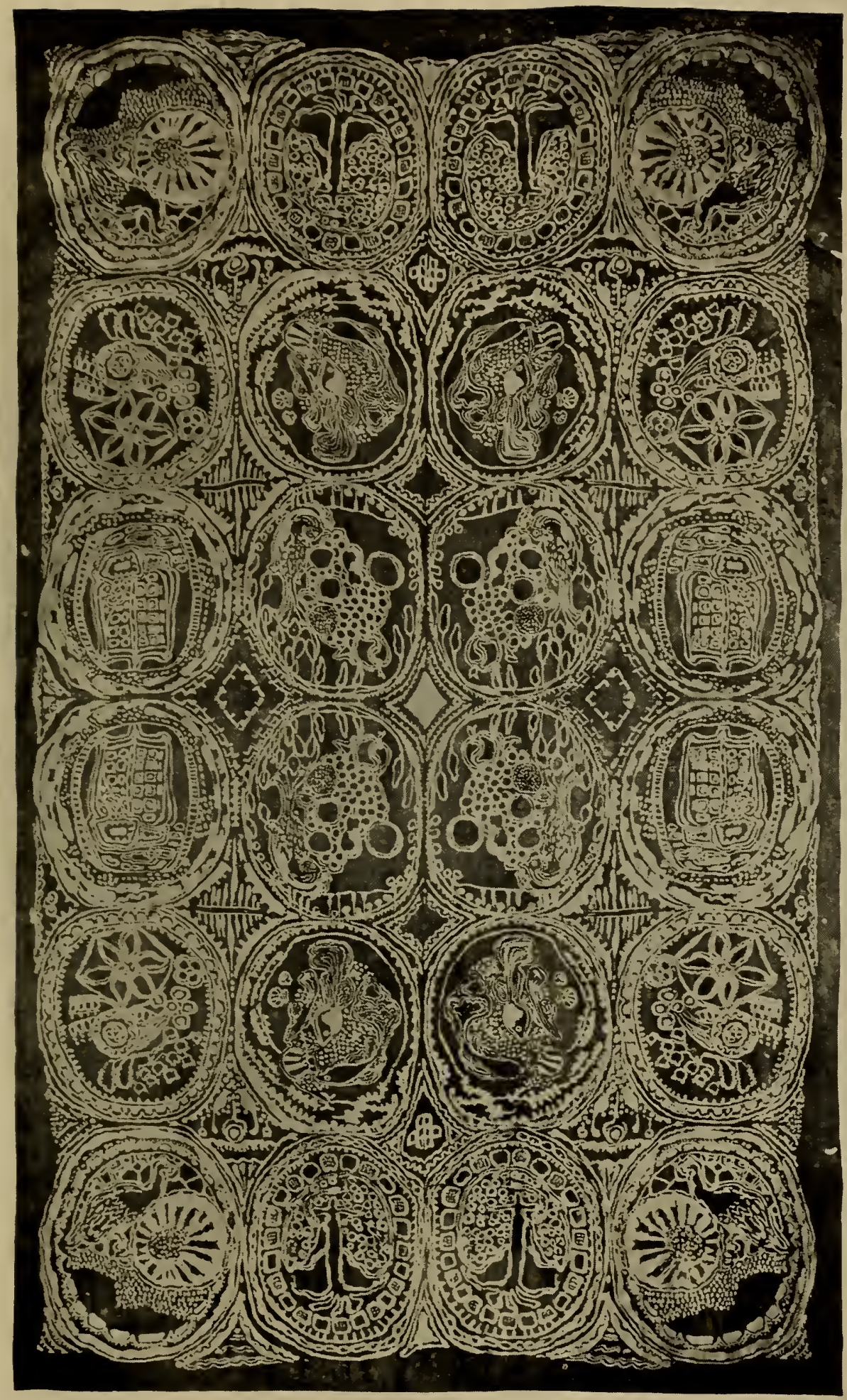

SCARF BATIKED BY HAZEL BURNHAM SLAUGHTER 

is usually the best plan to make the design on paper first, together with a coloured sketch to be used as a guide when the dyeing part of the process is reached. In using transparent material, the design can of course be placed underneath it and the pattern traced directly through, but this is not practical with heavier fabrics. When waxing very thin material such as chiffon, it can be doubled or in some cases even folded FOLDING in quarters, laid perfectly flat and the wax applied. This short cut was used in the batik illustrated facing page 50. It was designed and executed by Hazel Burnham Slaughter, and it is a representative piece of the beautiful work done by her on sheer materials. It is made with only two colours-the original colour of the chiffon, a very light tan, and a soft mellow red; the design is an arrangement of free ornament, floral and animal life. It is a free-hand all-over design, and repeats itself four times, having been folded as described above.

This folding process only has satisfactory results when very thin material is used as the wax will not penetrate through two or more 
thicknesses if the fabric has any weight at all.

The most satisfactory means of transferring the design, is to prick the outline with a pin, or wheel perforator, place the perforated paper on the fabric and rub char-coal through the holes. If one cannot obtain any charcoalthough one must be far indeed from the madding crowd to be out of reach of even charcoal tablets, lead-pencil dust can be used, though it is not at all to be recommended owing to the dirty smears that it makes when rubbed.

Be very careful to have the material quite straight and place the design on it squarely, or the final effect may be very twisted and distorted. If the pricking has left a jagged edge to the holes in the paper, rub the perforations lightly with sandpaper in order that the charcoal may go through cleanly and easily.

REDRAWING OF DESIGN
When the finished work is to be in more than one colour, it is advisable to strengthen the charcoal outline with pencil or Conté Crayon No. 2, otherwise it is washed off in the first dipping. This redrawing is not necessary if one wishes to have an undyed outline edging 
the different colours, as in that case the outline of the whole design will be drawn in, in wax, and this will permanently indicate the pattern.

The American method of working differs PREventing from the Javanese in the fact that the native hangs her material vertically in front of her when she is waxing her design, whilst the AmerTHE WAX FROM STIOKING ican is decidedly more comfortable with his material flat on a table. Usually it is stretched on a frame or canvas-stretcher to prevent it from coming in actual contact with the surface of the table whilst the wax is being applied. If it is not kept clear, it will be found that when an attempt is made to lift the textile, on the completion of the waxing process, it will be sticking in places and the wax torn in consequence; the effect of this damage will be that in dyeing the colour will penetrate from the back, and the material exposed by the breaks will turn out to be some shade quite unplanned for in the original scheme. For very big pieces, however, it is rather inpractical to use a frame and as an alternative to stretching, the fabric can be waxed on a table which is covered with 


\section{BATIKS, AND HOW TO MAKE THEM}

thin smooth paper; with careful lifting, little or no harm need be done to the wax, but in any case it is well to make a thorough examination of the reverse side in order to be sure that there are no exposed surfaces that should be retouched.

Some artists work with a sheet of glass under their material, instead of paper, but this, whilst having the advantage of not sticking as much has the great objection of rapidly cooling the wax with which one is working and cool wax does not penetrate the material properly.

CLEAN OUTLINE

HANDLING THE

TJANTING

A clean edge to the design is obtained with more certainty if the flat masses are outlined with a fine brush or preferably with a tjanting, before being filled in with the larger brushes. Where the work is done with a tjanting, it is difficult to have the fabric stretched on a frame as this tool is used with the palm of the hand resting on a steady surface. The illustration facing page 54 shows the way to hold the tjanting when the work is laid flat on the table. The wrist and the lower part of the hand rest on the table, the tjanting is held between the thumb 


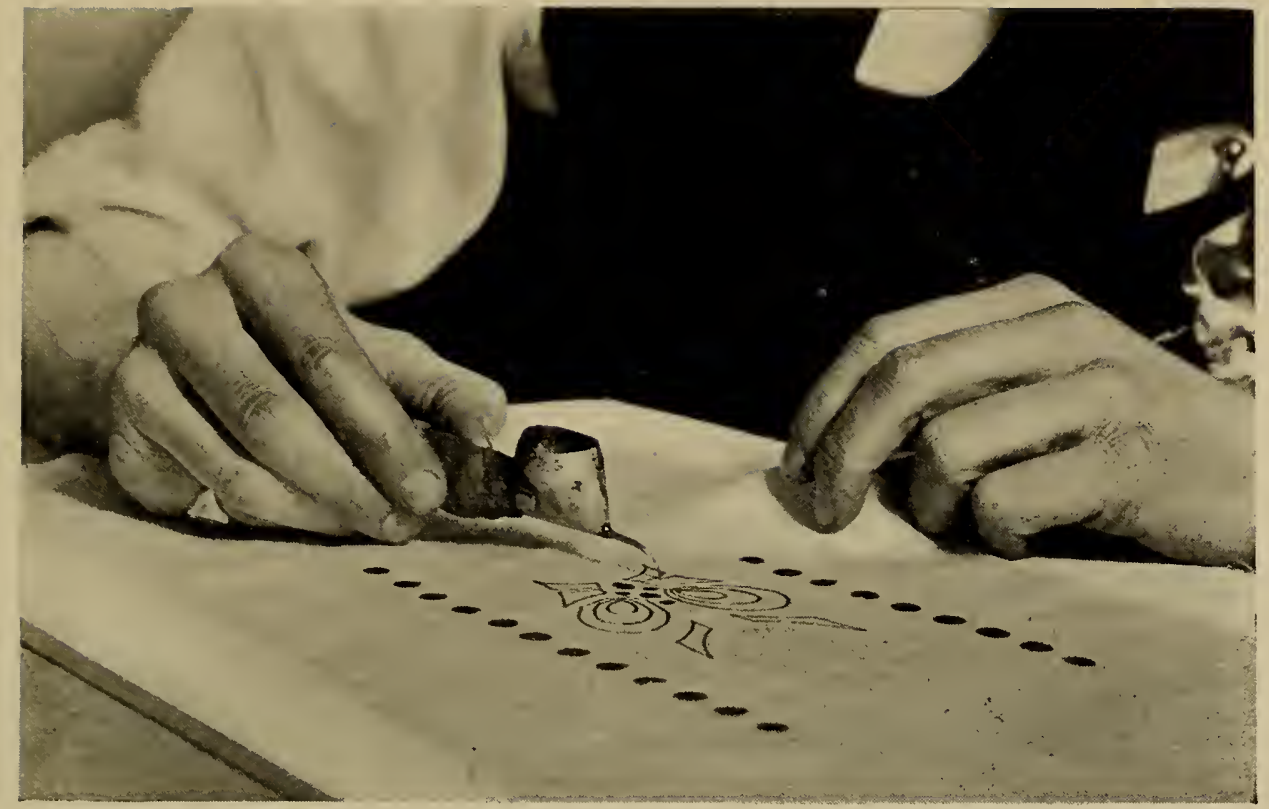

THE RIGHT WAY TO HOLD THE TJANTING

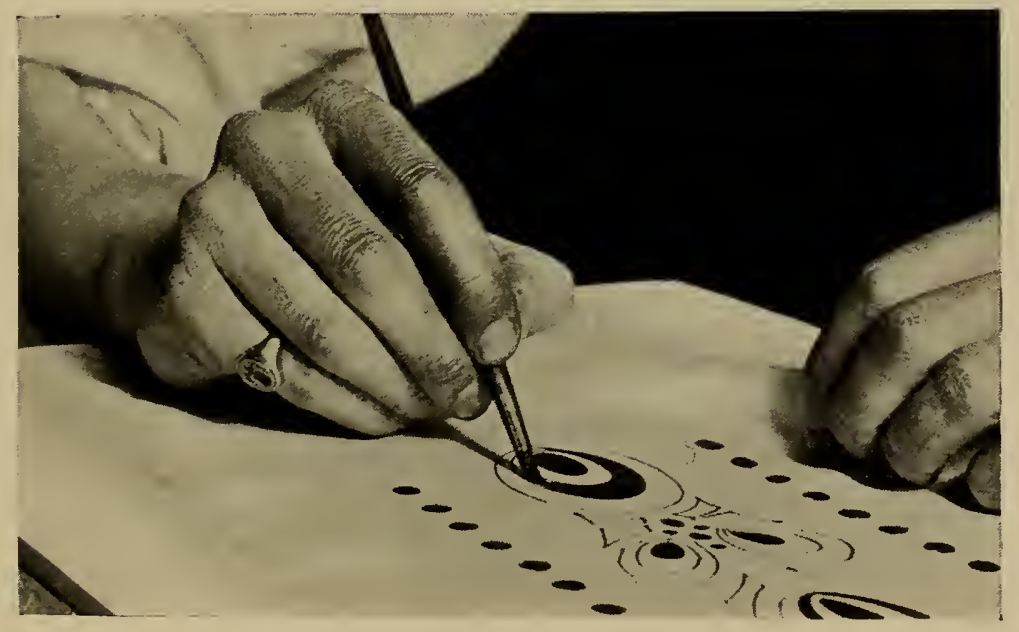

THE USE OF THE BRUSH FOR FILLING SPACES 

and the two first fingers, while the remaining fingers act as an additional support. All small movements can be made with the wrist remaining stationary; for big curves the hand and arm are slowly moved in the required direction, keeping the tjanting at an even level. Though in the beginning this may seem difficult, it will be found that after a little practice, it will be quite easy to make even and regular lines.

Having covered up with wax all the parts of the design which are to remain white or the original colour of the fabric (if an already dyed piece is used for the foundation) it is now ready for the first dye bath.

Select the lightest shade in the colour sketch for the initial dyeing. To be sure of getting the desired shade it is well to test a sample of the fabric. To do this, wet the piece and immerse it in the dye for a few moments; when it is dry it will be several shades lighter than when it is wet. One can get an approximate idea of the colour that a wet piece will be when it is dried, by looking at it against the light.

The simplest batiks, of course, are those in 
which only one colour is used and consequently only one dipping is required. Details of dyeing and the matter of colour schemes will be treated at length elsewhere in this book. After dipping, the material should be rinsed thoroughly in luke-warm water. Avoid the use of cold water, especially when another dyeing is to follow, as the cold will cause the wax to become brittle and crack, and unintentional crackling is a sign of poor craftsmanship. If the batik is to be in only one colour it is now ready for the removal of the wax, which is a simple business, consisting of rinsing the fabric very thoroughly in gasoline or Carbona.

More elaborate colour schemes are produced by a repetition of the process, simply covering up with fresh wax the parts one wishes to retain in the shade of the last-dyed colour. This re-waxing, dipping and rinsing is continued until all the colours that the scheme demands are obtained, and then the wax is removed as described.

A word here on the use and mis-use of gasoline may be in order. Gasolining should be 
done very thoroughly; one of the faults common to all amateurs is insufficient rinsing and the fabric still stiff with wax is placed on the market as a finished product. Often the lovely softness of a drapery will be lost and a papery quality substituted just because there have not been a sufficient number of gasoline baths used.

When possible, gasoline should be used out of doors, although if proper precautions are PRECAUtaken, there is no reason why people should be TTONS nervous about using it in the house. In the first place do not use it in a room in which there is a fire burning and do not imagine the room is safe for a lighted match immediately the vessel containing the gasoline has been removed. Gasoline fumes are heavier than air and if undisturbed will hang low in the room for some time; it is therefore a good plan to have the window open slightly, at the bottom as well as at the top, in order to create a current of air. The hot air rising and the fresh air coming in at the bottom of the window, will soon disperse the fumes.

Have the gasoline in an earthenware vessel. 
Enamelware easily gets chipped and the exposed iron when touched by the hand may give a slight electric shock, as electricity is sometimes generated through rubbing the fabric. It is well, in any case, to avoid hard rubbing and to use as little friction as possible, taking particular care on bright clear days when the air itself seems charged with electricity. GasoECONOMY line can be used over and over again. The last baths for one batik, containing only a small amount of dissolved wax, can be used for the first bath next time, and with an apparatus similar to that illustrated, it is quite easy to run off the dissolved wax (which sinks, being heavier than the gasoline), and save only the clear fluid.

The last stage of the process is the ironing, which needs no more description than the suggestion that the work is placed between papers; this hint may prevent the streaking which sometimes ruins a batik that has successfully survived the various stages of a decorated textile's creation. 


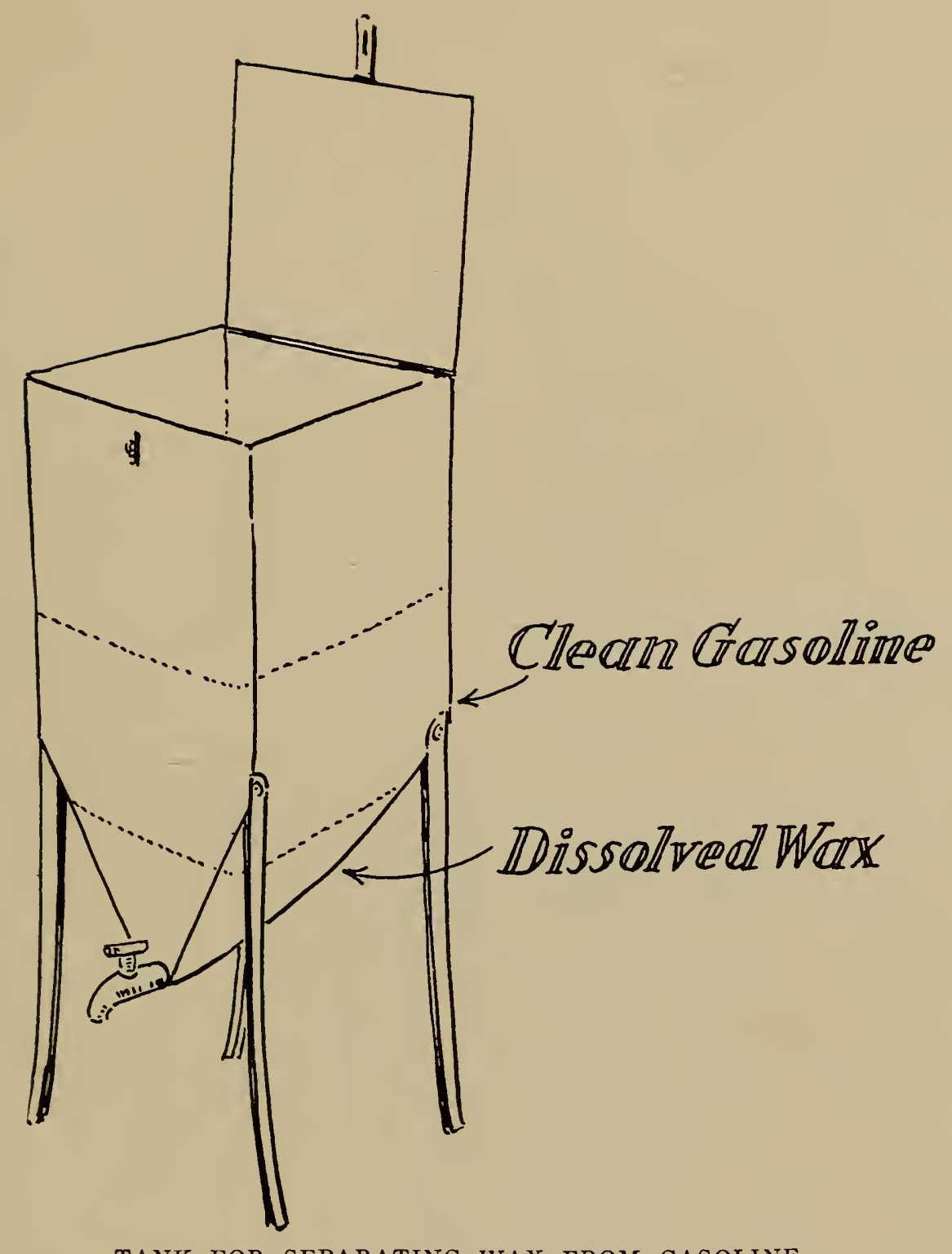

TANK FOR SEPARATING WAX FROM GASOLINE 



\section{SUCCESSFUL DYEING}

A GOoD deal of the failure of success attending the dyeing of a batik depends on the temperature of the dye-bath. Too hot water will of course melt the wax and a too cold bath will make it so brittle that it will crack in unexpected TEMPERATURE OF DYEBATH and undesired places. The accompanying scale of temperatures shows the corresponding degrees of heat on different thermometers. When pure bees-wax has been used the dye bath can be brought to and maintained at a heat of $110^{\circ}$ Fahrenheit, corresponding to $46^{\circ}$ Centigrade or or $36^{\circ}$ Reaumur. If a mixture of paraffin has been used, it is not advisable to have the dye at a higher temperature than $90^{\circ} \mathrm{Fahr}$.

TABLE OF TEMPERATURES

\begin{tabular}{c|c|c|c|c|c}
\hline $\begin{array}{c}\text { Centi- } \\
\text { grade }\end{array}$ & $\begin{array}{c}\text { Reau- } \\
\text { mur }\end{array}$ & $\begin{array}{c}\text { Fahren- } \\
\text { heit }\end{array}$ & $\begin{array}{c}\text { Centi- } \\
\text { grade }\end{array}$ & $\begin{array}{c}\text { Reau- } \\
\text { mur }\end{array}$ & $\begin{array}{c}\text { Fahren- } \\
\text { heit }\end{array}$ \\
\hline 30 & $24 .-$ & $86 .-$ & 39 & 31.2 & 102.2 \\
31 & 24.8 & 87.8 & 40 & $32 .-$ & $104 .--$ \\
32 & 25.6 & 89.6 & 41 & 32.8 & 105.8 \\
33 & 26.4 & 91.4 & 42 & 33.6 & 107.6 \\
34 & 27.2 & 93.2 & 43 & 34.4 & 109.4 \\
35 & $28 .-$ & $95 .-$ & 44 & 35.2 & 111.2 \\
36 & 28.8 & 96.8 & 45 & $36 .-$ & $113 .-$ \\
37 & 29.6 & 98.6 & 46 & 36.8 & 114.8 \\
38 & 30.4 & 100.4 & & & \\
\hline
\end{tabular}


THE USE OF TOO MUCH DYE

A fault with amateur dyers is that they often use a great deal more dye than is really needed. By this, it is not meant, that too much solution is used, but too much of the actual colouring matter. One ten cent package of dye will dye a pound of material; some fabrics, such as a light weight silk run about sixteen yards to the pound. To avoid any waste of dye, it is a good plan to prepare a concentrated solution in a small pan and use it with care and economy. Do not add it all at once to the water in the large vessel, but rather make a weak bath into which the piece is put, after having been rinsed in clear water and squeezed out. When the colour is all taken up from the bath, remove the fabric and add more of the concentrated solution. Do this several times rather than impatiently pour in the whole strength; when finally the desired intensity of colour is reached, it will be found that the dyes are faster and a great deal less colour will have been used than would have been the case otherwise. If careful judgment has been used, the water will be practically clear at the end of the proceedings. 
Another good reason for not using too strong sTREAKS IN a bath is that with a weaker solution it is much DYEING easier to avoid the streaks that annoy the inexperienced dyer. The use of too small a vessel is a frequent cause of uneven dyeing; the material should literally swim in the tub so that no dye can possibly settle in the folds, and for this same reason it is essential to keep the goods stirred the whole time they are in the dye.

After the material has been removed from the RINsina dye-bath, it should be rinsed very thoroughly and dried. A large piece can be quickly dried when one knows how. Do not wring it on any account or the wax will be broken in a thousand pieces. Old sheets and towels can be requisitioned with good effect; wrap the rinsed material in these to absorb the heaviest of the moisture and to prevent dripping. If the material is allowed to drain and has not been rinsed properly, the appearance of the dreaded streaks will at once show the reason, why the rinsing part of the process is emphasized When thus "blotted" the material will soon dry 


\section{BATIKS, AND HOW. TO MAKE THEM}

when hung over a waxed non-absorbent clothesline; an unwaxed line will sometimes leave a mark where the fabric has touched it.

REWAXING

The material should be thoroughly dry before the second waxing is applied. If an attempt is made to do it while the goods are still damp, it will be found that the wax does not penetrate so well, and consequently, in the second dipping the dye will seep in through the back and spoil the colour which the wax was intended to preserve.

"ORACKLE" A crackle effect can be produced all over the design by crushing the fabric, more or less gently, according to the amount of colour that one wishes to allow to penetrate, just before the last dipping. A local crackle can be obtained similarly, by crushing only those parts where a broken-up surface to the design, is required.

The occasional use of "crackle" will help the artist a great deal,-for instance, it may happen that one of the light colours in the design may turn out to make too glaring a spot to be entirely harmonious and in such an event 
one may get pleasing results by deliberately crackling that particular spot and thus tone down its brightness.

Instead of dipping their batik several times, some people paint in some of the colours. As a PAinting IN COLOURS rule this local application of dyes is resorted to when multi-coloured batiks are desired and when red and blue are used in the same colour scheme. The results of this method of dyeing are not, however, very satisfactory, as it always shows in the finished piece. No matter how small the painted-in spots may be, they always seem to stand out and do not harmonize with the general scheme, the way colours do that have been dyed over each other, as, having been dyed over each other the darker tones are a composite of the colours dyed previously and the whole effect naturally shows a pleasing relationship of colour.

The Javanese occasionally put in their extra colour by this means, but with no greater success than the American artists and the finest craftsmen there are not using the painting process at all. 


\section{BATIKS, AND HOW TO MAKE THEM}

Another drawback is, that not only are the colours inharmonious, but the moment you try to paint in any large surface, that is, any area bigger than a square inch, the colour is always uneven; this is because the moment the silk is touched with the brush, that individual spot gets the full strength of the dye, which fades out toward the edges and no matter how much patching up is done, it is impossible to get a perfectly even surface such as can be obtained by dipping. Of course, the dye when painted in, is cool and the colours will not be as fast as when the fibres of the material slowly absorb the hot dye. Among other disadvantages, is the fact that the spot which is to be coloured, always has to be first outlined in wax to prevent the dye from spreading; this gives a light outline round a dark surface, which, while not spoiling some designs has an unpleasing effect more often than not.

COLOUR GROUPS

Batiks in one or two coloury are of course much simpler than those in which a variety of tones are required, but with a little thought and practice many colours can be used together on 


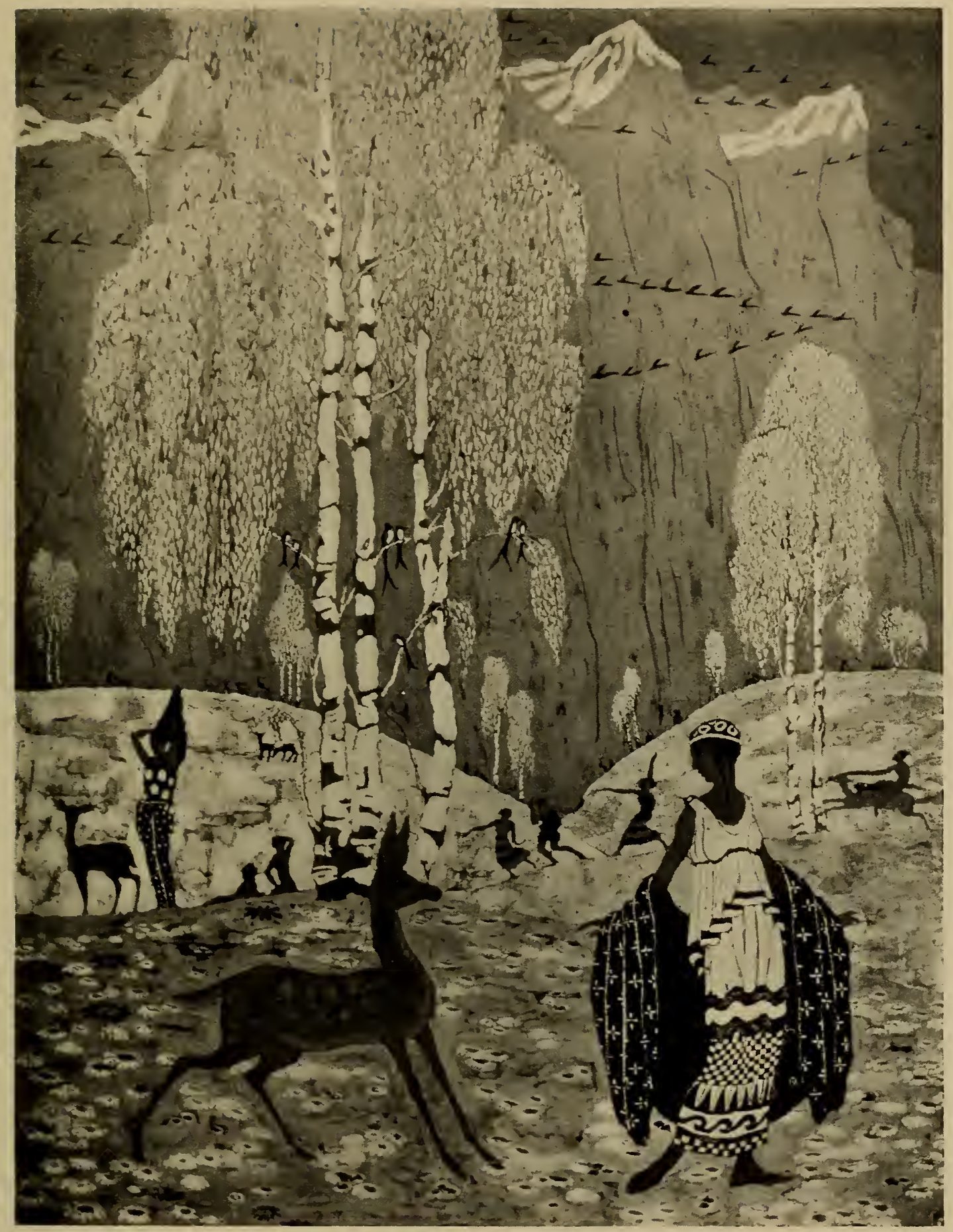

"SPRING" BY C. BERTRAM HARTMAN AND PIETER MIJER 

the same piece. The simplest colour scheme consists of an arrangement of yellow, green and blue. Always start dyeing the lightest colour first and work through the colour plan to the darkest shade; for instance, in a piece where yellow, red and black are desired, the dye-baths are arranged in the same order.

In the use of dyes it is necessary to arrange the colour ranges into two groups, which we will call the "group of the reds" and the "group of the blues." The "group of the reds," starts with yellow and its variations and hues, then red and variations of red, and lastly purple. The main colours of the "blue group" are yellow, green, blue, and purple. This division of colour will be readily understood by those who have some knowledge of the subject it will be clear to them that red can be dyed over yellow, and purple can be dyed over red in its turn, whilst it would be impossible to produce a good blue or green on top of a previously dyed red. This same idea holds good in the group of the blues.

"Spring," the panel illustrated facing page 
64, designed by Bertram Hartman and executed by him and the writer, is one of the early batiks designed by this artist. It was dyed in the group of the blues and no reds were used in the making of it. It was dipped eight times, the original white of the material making the ninth color. The waxing of this piece was done entirely with the brush, no tjanting being used, and gives a fair idea of the fine work that can be done with the brush, if one considers that the size of the original panel is only about forty by sixty inches.

EXTRACTING COLOUR

For some designs it may be necessary to use both red and green in the same piece; in this case the colours of the "blue group" should first be dyed, until the darkest shade called for in the colour scheme has been obtained and then the colour can be extracted from the places where the shades that belong in the "red group" are demanded. With the strong colour extracted, it is possible to get the opposing colours quite successfully, starting in with the lightest tones and working through to the darkest in the manner already described. 
This bleaching can be done with a solution of ammonia or washing soda. Both these mediums have to be used with the greatest care as either of them will eat into the wax to a certain extent and consequently allow the next colour to penetrate and affect the previous dyes. It is wise, therefore, to inspect the waxed off parts very carefully before re-dyeing and retouch the places where the wax has been destroyed. A good plan is to keep a strict eye on the wax in any case, in order to prevent surprise attacks by dye on the material through places that have become weakened. Naturally the wax is likely to suffer when the fabric has to be handled as much as it has to be, when being dyed a number of colours.

Some people, when they wish to have opposing colours, such as blue and red, in the same design, resort to the native method of removing the wax entirely after each dipping and re-covering the parts already dyed. This takes a great deal longer and the wax needs very careful dissolving, as the fresh dye will not "take" unless every particle of it is removed from the 
fabric and even then it is not easy to get a successful dipping as the gasoline used for the dissolving is more or less greasy and of course grease has no affinity with water. White lines, or lines the colour of the original fabric, are apt to show too, if one has overstepped the boundary when covering up the first colour, prior to the second waxing.

When dyeing a batik with one colour over the other, the second colour dyed will always be affected by the tone of the first dipping; for instance, suppose your material is dyed yellow the first time, and blue the second, the fabric will not come out as a true blue, but according to the strength of the blue dye, will be either light green, green blue, or if an intense blue has been used, a blue-green will result. It will be found that similar variations will occur when red is dyed over yellow, which will give shades of orange and gradations of purple will be obtained when red is dyed over blue.

A careful study of the accompanying colour mixing chart will give the reader an idea of the 


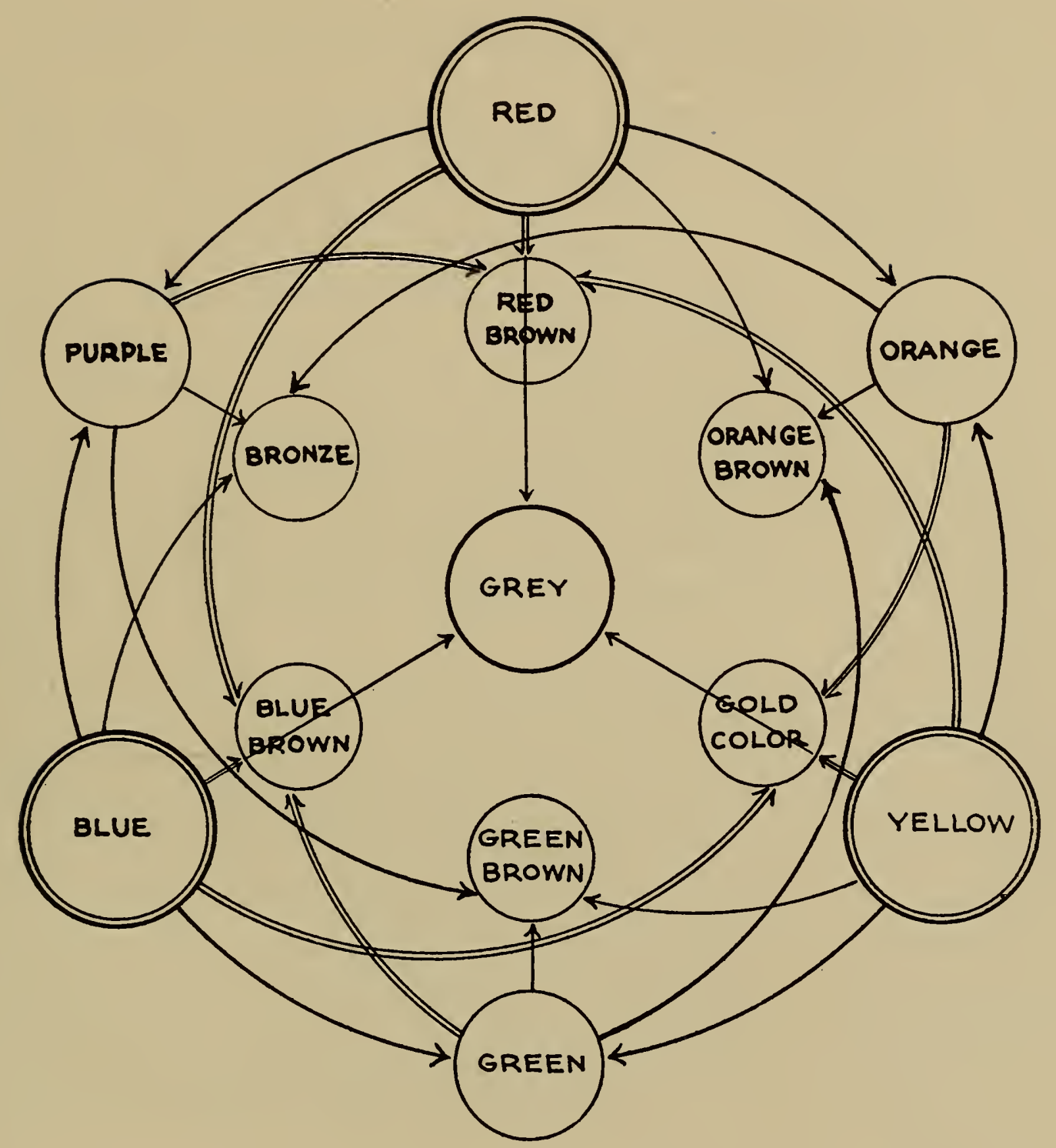

BY FOLLOWING THE ARROWS IN THE ABOVE CHART IT WILL EASILY BE SEEN WHICH COLOURS SHOULD BE MIXED TOGETHER IN ORDER TO PRODUCE A GIVEN COLOUR. THE PROPORTION OF DYE USED IS INDICATED BY THE CONNECTING LINES; THE SHORTEST LINE SHOWS WHICH COLOUR SHOULD PREDOMINATE 

way various shades are produced from the primary colours.

The three primary colours are red, yellow and blue.

THE COMPOSITION OF COLOUR

Red mixed with yellow produces orange. Yellow mixed with blue produces green. PRIMARY Blue mixed with red produces purple. AND SECONDARY COLOURS

The orange, green and purple are known as the secondary colours and by mixing either the three primary or the three secondary colours together, grey is obtained. It would therefore be quite possible to dye successfully, with a stock consisting of only the three primary colours, but it certainly would be a waste of time.

For several years the writer worked with five colours, red, blue, yellow, brown and black, and with these produced the various tones necessary in a multi-coloured batik. It is, however advisable to have a few more shades in stock; and with the following selection it is possible to make the widest range of colour in a very short while, and the writer has found that the best results are obtained with the following: 
DYES AND DYE MANUFACTURERS

Roccelline 2578J, Natl. Aniline \& Chemical Co., Inc., 21 Burling St., N. Y. C.

Orange extra, 2578J, Natl. Aniline \& Chemical Co., Inc., 21 Burling St., N. Y. C.

Azo flavine, Bachmeier \& Co., 438 West 37th St., N. Y.

Chenoline yellow, Bachmeier \& Co., 438 West 37th St., N. Y.

. Victoria green, Dicks David Co., 299 Broadway, N. Y.

Acid green, Bachmeier \& Co., 438 W. 37th St., N. Y.

Indigotine, Bachmeier \& Co., 438 W. 37th St., N. Y.

Oxaline black, H. H. Metz \& Co., 122 Hudson St., N. Y.

Alphanol brown B, Natl. Aniline \& Chemical Co., Inc.

Magenta, H. H. Metz \& Co., 122 Hudson St., N. Y.

ACIDS

Most dyes used in batiking are set with either sulphuric or acetic acid. The above list is all used with the latter, which is preferable, as sulphuric is very dangerous; the slightest trace 
left in the fabric will, after a while, rot the fibre. Acetic acid does not harm the silk, but with some dyes it is too strong and will change the colour. If this should be the case, either tartaric or oxalic acid can be used. In most cases the acid is added to the bath of the diluted dye rather than to the concentrated solution, the exception being in the case of the Victoria green and the magenta; these have to be dissolved in acetic acid before they are put in the water. Acetic acid is obtainable from any druggist.

Some dyes are set with salt and it is used with many of the household dyes which are always sold with directions on the package. When buying direct from the manufacturers, their chemists will always give the necessary information as to which acids should be used with the various colours.

This book is not intended to be a technical treatise and readers who wish to know more of the chemistry of dyeing are advised to study Prof. Chas. E. Pellew's "Dyes and Dyeing:"

The tertiary colours are all in the brown tones TERTIARY and the following table may prove a useful colours guide. 


\section{BATIKS, AND HOW TO MAKE THEM}

Blue + orange + yellow produce gold.

Red + green + blue produce blue-brown.

Yellow + purple + red produce red-brown.

Green + orange + red produce orange-brown.

Orange + blue + purple produce bronze.

Purple + yellow + green produce greenbrown.

It would not be possible to give weights and measures of the different colours, as such specks of colour will change the tone, but any one wanting to mix colours for matching will find that it takes very little time to get a colour once he has decided what the nearest colour is, on the colour chart. By studying this, it is easy to find out what colour should be added to produce any given shade.

MATCHING COLOURS

The most difficult problem in dyeing is the matching of colours when the materials are different. For instance it is not easy, on account of the difference in surface, to match a charmeuse to a given plush or velvet.

For beginners it is always best to start experimental dyeing by daylight, unless one has a very white light, as the yellow of artificial 
light takes all, or very nearly all the yellow out of a colour, with the result that where one at night has a beautiful blue, this blue will turn to green in the daytime and lavender will invariably turn grey.

Yellow is sometimes rather a difficult colour to manage, that is to say that if, in a batik the COLOUR original white of the material is to be used as a background for a design in yellow, it will be very difficult to see where the white finishes and the yellow of the decoration begins. While the material is wet the design will show, but when it is dry, by some mysterious trick of the eye, it has apparently vanished; it is therefore advisable to use a second colour to offset either the white or the yellow.

If, however, a second colour is not desired in the batik and consequently have nothing to offset the yellow, the following hint will save the situation; a little blue or a little red, mixed with the yellow solution, will enable the yellow to hold its own on the white ground. The slightest touch of either of these colours will have the desired effect. 


\section{BATIKS, AND HOW TO MAKE THEM}

When the colour scheme calls for a yellow and a blue as separate colour units in the design, and the blue is wanted after the yellow dipping, the effect of the yellow on the blue (which produces green) can be diminished by dyeing first, a very weak solution of magenta, over the yellow. Rinse the material thoroughly, then proceed to dip in the blue dye-bath. In doing this, it is necessary to be very careful with the magenta, as it is a very strong colour and an overdose will be liable to produce a purple instead of a blue. Of course, if the original yellow is very intense it is not possible to neutralize it in this way and the bleaching process will have to be used, in order to obtain the blue.

And this is another good thing to remember in making a multi-coloured batik which is to have white as part of the colour arrangement. It is always advisable to dye the original white of the fabric some very pale shade, either grey, light tan, pale blue or even pink. If the material is used in its original pure white state, a pleasing effect will never result, as the white 


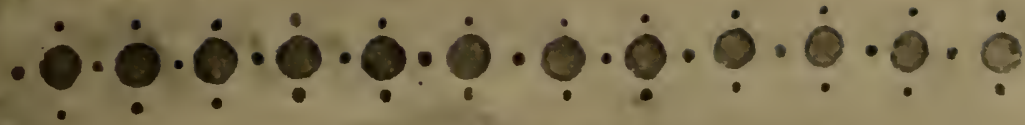

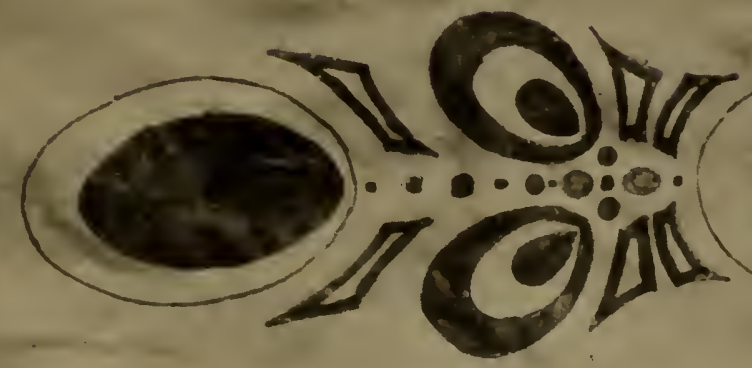

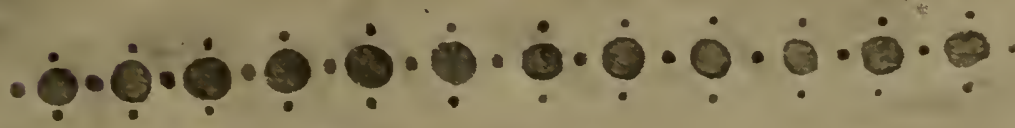

$\circ \circ, 0 \circ 0,000$

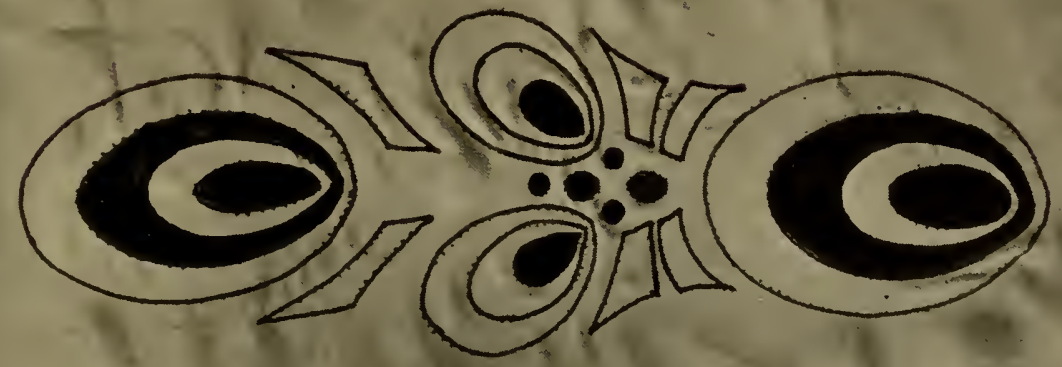

$\bullet \bullet \bullet \bullet \bullet \bullet \bullet \bullet \bullet \bullet \bullet \bullet$

$\ddot{\dot{x}}$

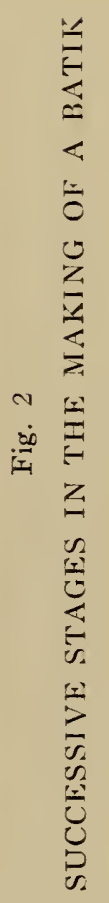

000000000000

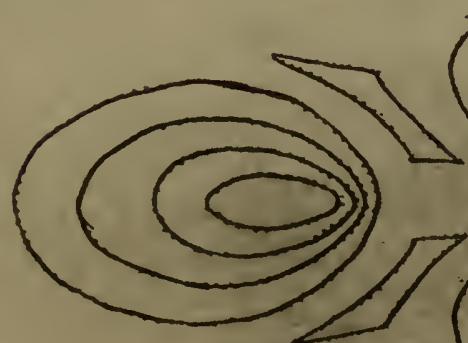

(a)
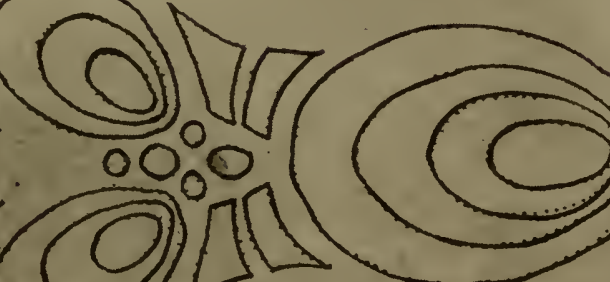

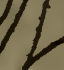

2

- 

will always stand out as a glaring hard spot when it is next to colours that are dyed over each other and consequently blend harmoniously. This preliminary all-over dyeing will "tie in" the white and make it in key with the rest of the scheme.

The series of photographs shown here represents the successive stages of a batik in the making. The original fabric is white silk and the first step is the pouncing on, of the design with charcoal, which is then strengthened with pencil. With the tjanting this outline is then waxed (Fig. 1). The spots which are to be white in the completed design, are now filled in with the brush and the material is given its first dyeing, yellow (Fig. 2). Now all the parts that are to stay yellow, are covered off with the wax; when this waxing is completed the material is dipped in light blue, which being dyed over yellow, will produce light green (Fig. 3). After drying, all that has to stay green is covered off with wax (Fig. 4). The final dipping is in red. The last picture (Fig. 5) is the com- 


\section{BATIKS, AND HOW TO MAKE THEM}

pleted piece after the wax has been removed by gasolining; this photograph distinctly shows, in its variations of tone, the different colours that were used. 


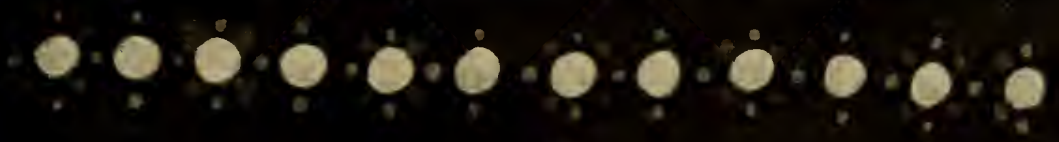

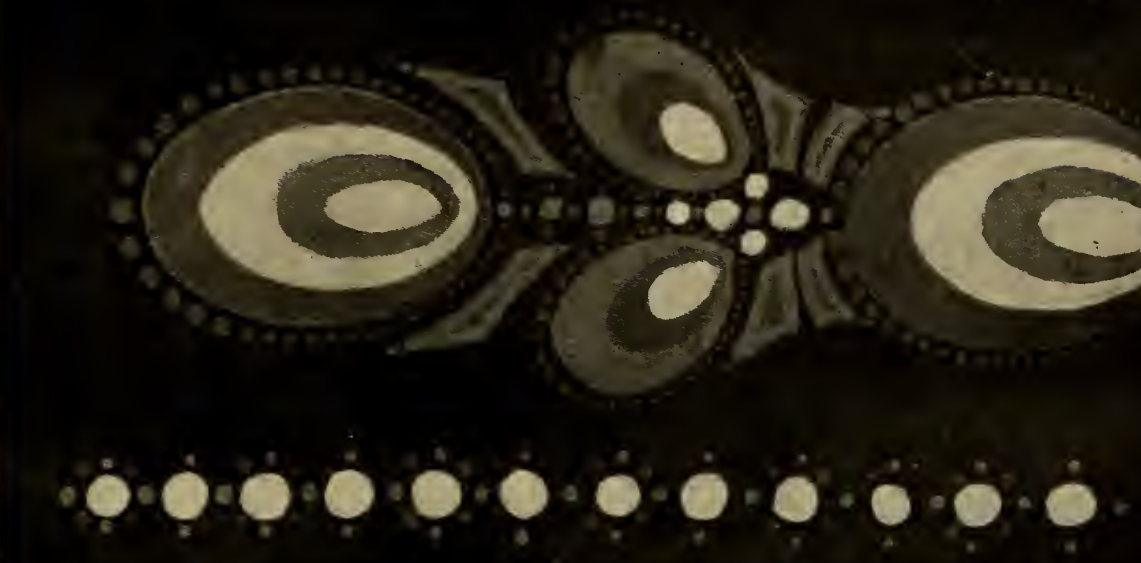

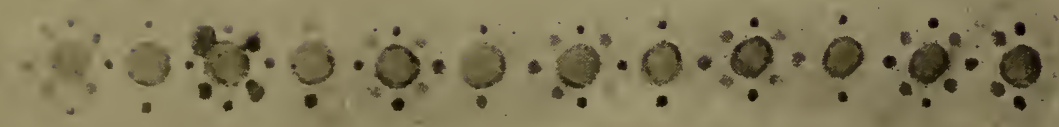

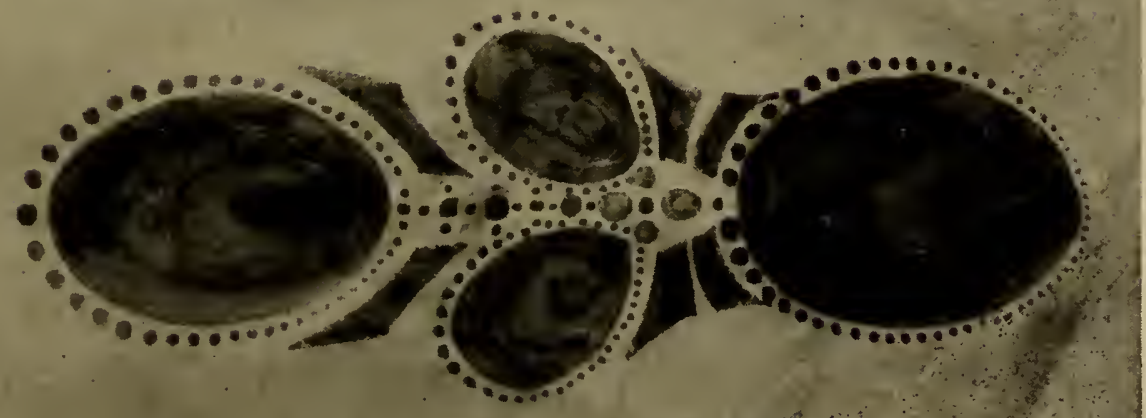

$\ddot{0} \cdot \dot{0} \dot{0} \dot{0} \cdot \dot{0} \cdot \dot{0} \cdot \dot{0} \cdot \dot{0} 0$ 



\section{THE VALUE OF A DYE RECORD}

A DYE record is an invaluable asset to a batiker; it is very little trouble to make and the time spent on it will easily be saved when future work is to be speeded up or samples are being made. A record book will prove its value in many ways, particularly if the batiks made are liable to be re-ordered, as for instance, when gowns are decorated for the trade, or if the making of one batik leads to a demand for a second, which perhaps is wanted with the same colour effects although not the same design. It is a good plan, therefore, to leave an extra strip of material on the piece that is to be batiked, or to pin a piece to the fabric which is to be decorated and let it go through all the different baths and processes, each time taking off a small sample of the new colour to be pasted in the record book.

As will be seen from the record quoted here, 
78 BATIKS, AND HOW TO MAKE THEM

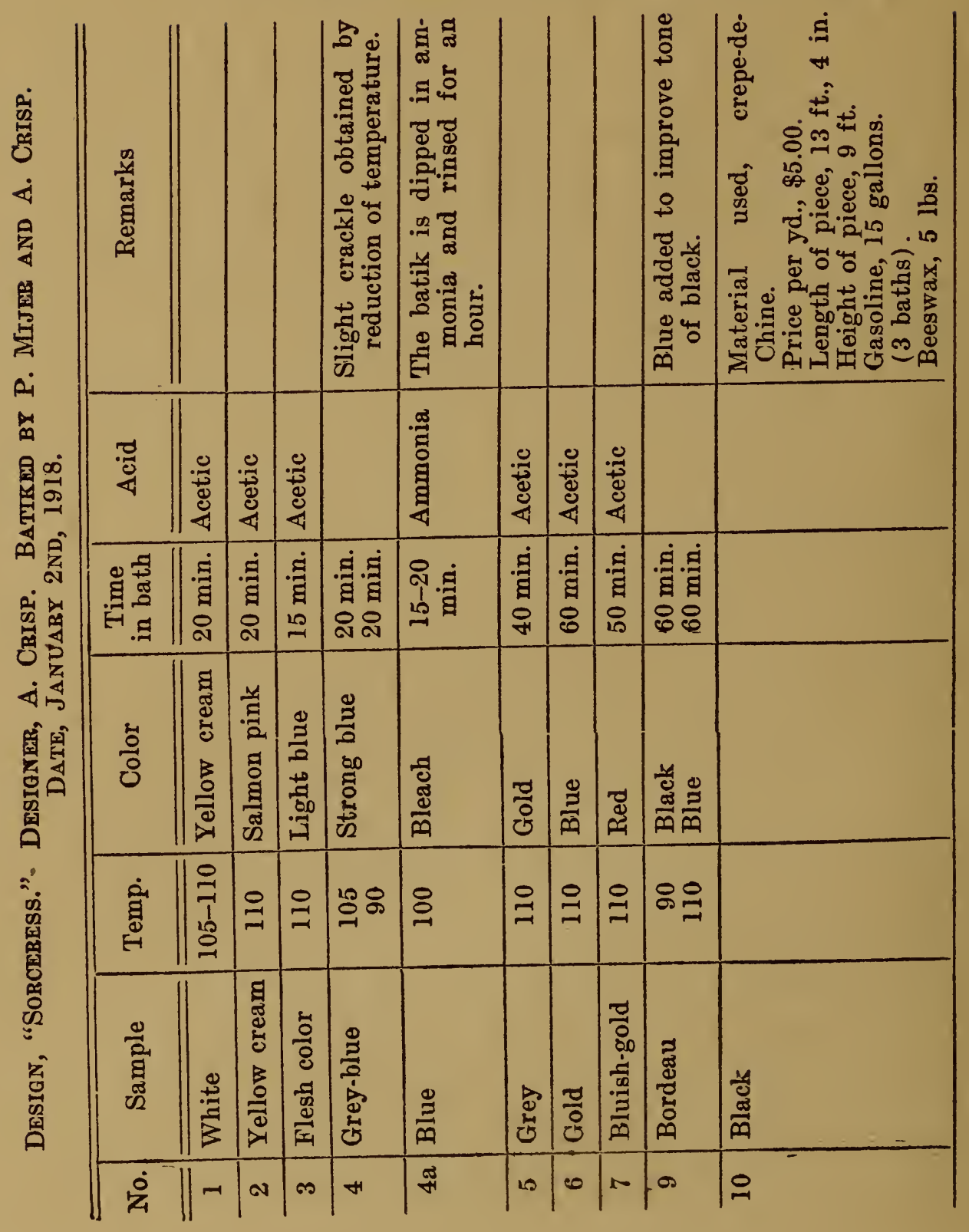




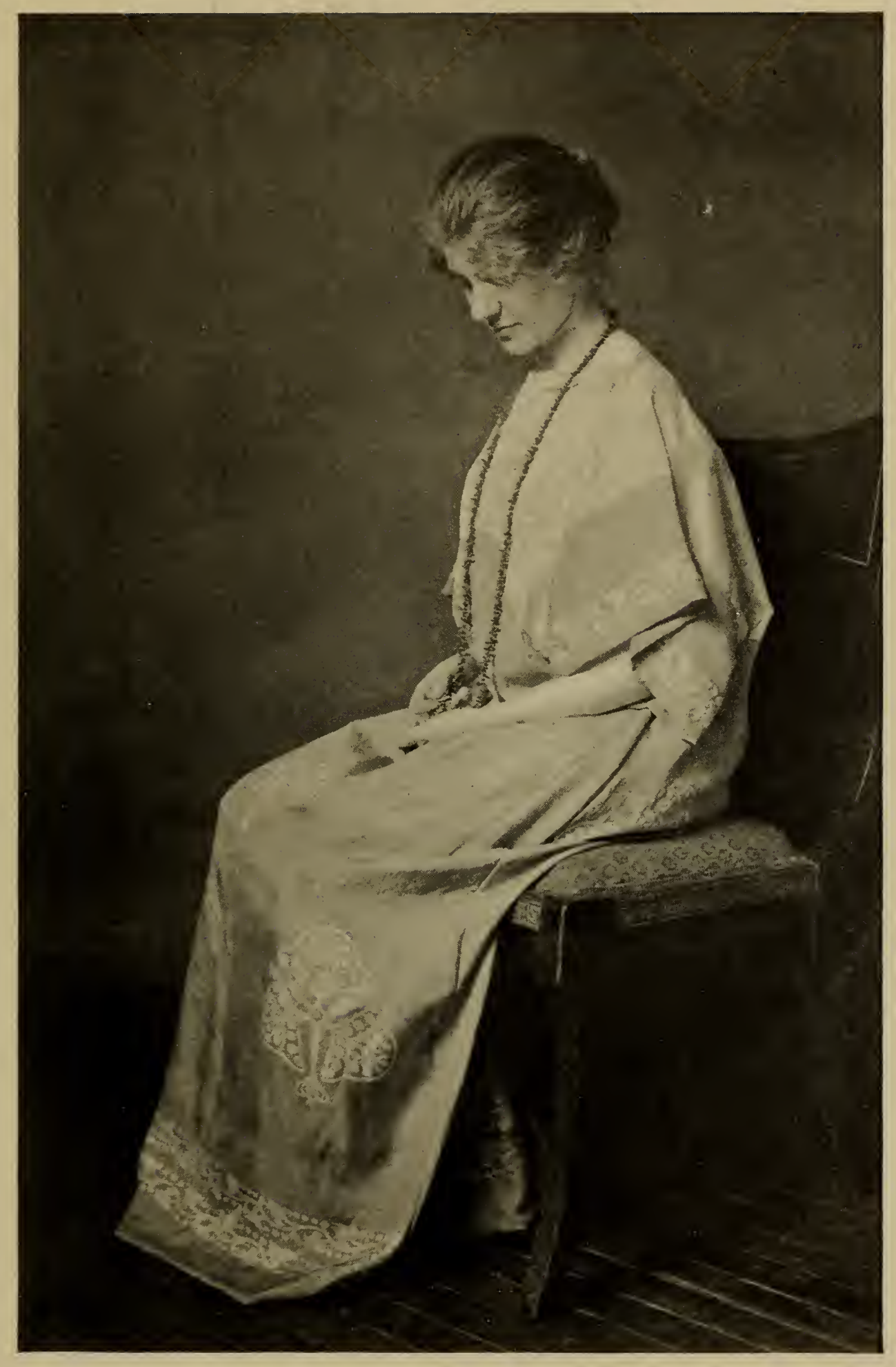

THE USE OF BATIK FOR COSTUME 

every detail is marked down-the temperature, time of dyeing, price of material and where it was bought, in fact any little item that may be of help later. A full explanation of this sample page may be of service to some readers.

The record shows the process of dyeing in the making of the "Sorceress" panel, shown facing page 78. The silk used for this panel was a very heavy Japanese crepe and the design was worked out in nine colours. That is to say, it was dipped eight times, the ninth being the original white of the silk. The only places where this original white shows is in a few little flowers in the branches of the trees, and these, on account of the many times the piece was dyed, have so much crackle in them that they do not appear as pure white.

The piece was first dyed a very light creamy yellow colour; this tone being composed of yellow, a speck of blue and a speck of orange. The mixture of these colours produces gold and a much diluted solution results in a straw yellow. The temperature for this bath was between $105^{\circ}$ and $110^{\circ}$ Fahr., and the time for dyeing 
about twenty minutes. After having been rinsed and dried, the parts of the design that were wanted the straw colour were covered in wax, the largest surface being the scarf of the Sorceress.

The panel was now ready for the second dipping. This was a light salmon pink, which over the straw-yellow gave the flesh colour for the face and body; this tone also appears in the light outline of the smoke and clouds. This salmon colour was made of orange and yellow mixed and was used very light. Temperature $110^{\circ}$; time, about 20 minutes.

The third bath was blue. This was used in the mountain in the background and in some of the leaves in the foreground on the piece. The blue was used pure, but not very strong. With the flesh colour, this gave a greyish blue. Temperature $110^{\circ}$. Time 15 minutes.

The fourth colour was the same blue, only much stronger, and in this the trees in the mountain, the outlines of the mountain and the stems of the bigger leaves were dyed. The fabric was in this bath altogether about $40 \mathrm{~min}$ - 


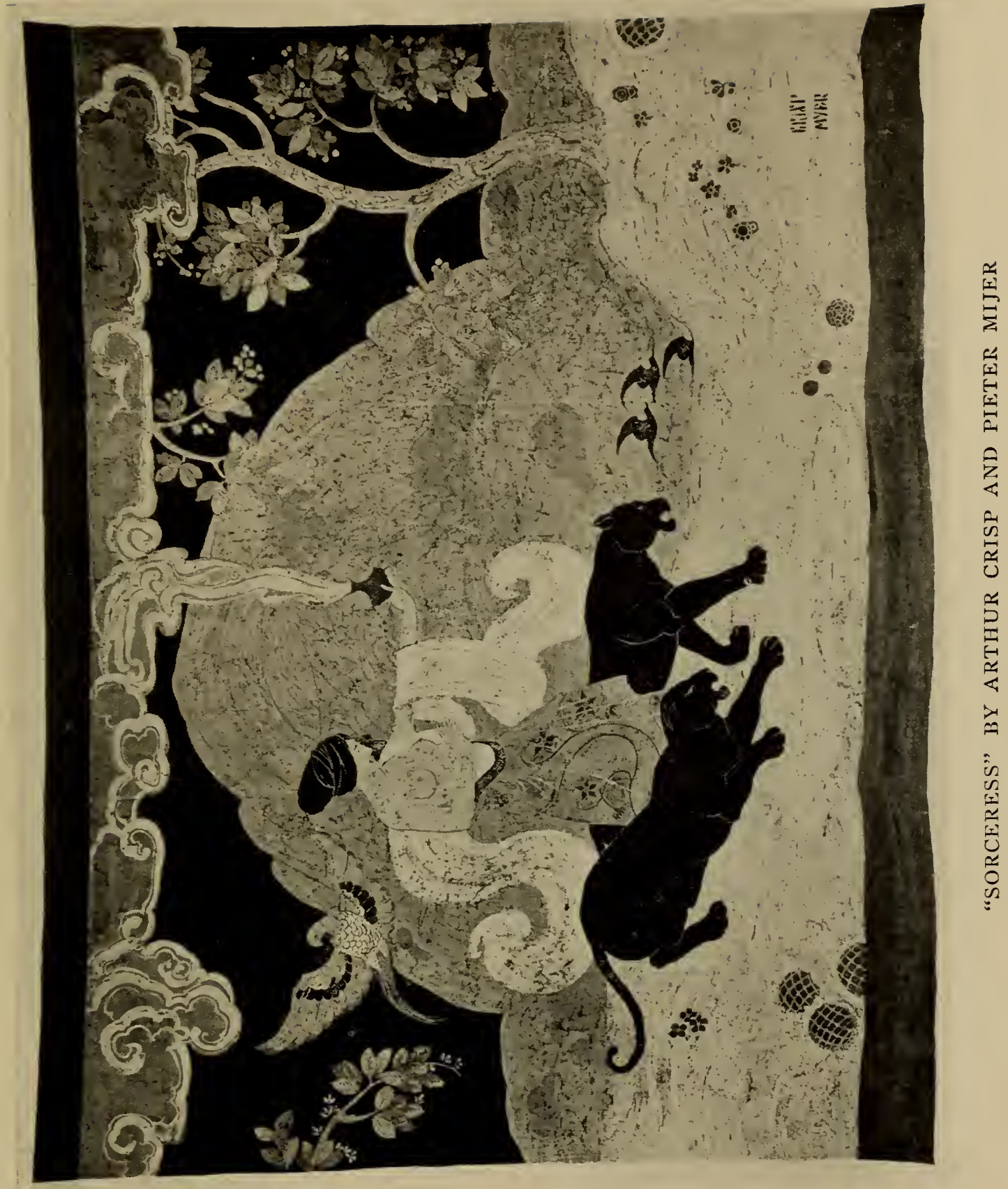



utes. The first half of this period the temperature of the dye was about $105^{\circ}$ and was reduced to $90^{\circ}$ for the last twenty minutes. This difference in the temperature was made in order to make the wax brittle and obtain a slight crackle to allow the penetration of the colour.

The crackle effect was not desired all over the design, so a second covering of wax was applied in some parts, after the material had been thoroughly dried. The face and body of the figure, in particular, were carefully gone over, as these parts had to remain as little as possible affected by the darker colours.

The panel was now dipped in an ammonia bath to extract the colour from the parts not covered by wax. This took from 15 to 20 minutes with a temperature of $100^{\circ} \mathrm{Fahr}$. When the color in the fabric was reduced to a light grey, the piece was transferred from the ammonia bath to a tub of clear water at the same temperature, and rinsed thoroughly for at least an hour, in order to remove every trace of the ammonia. After drying, the whole panel was carefully gone over to close all undesired cracks 


\section{BATIKS, AND HOW TO MAKE THEM}

that had come during the colour extracting process; these were mainly in the figure and the scarf.

No grey was used in the panel, therefore after the flling in of the cracks, the piece was ready for the fifth bath. This was the gold used for the foreground, and it also makes the highlights in the leaves and in the tree-trunks. This gold was obtained by mixing yellow, orange and blue, with the yellow as the dominant colour. Temperature, $110^{\circ}$. Time, 40 minutes. The sixth bath was the same gold solution, strengthened up with blue but without the addition of any more orange or yellow. This colour was used in the leaves, some parts of the trees, the wings of the parrot and the solid colour of the skirt. Temperature, $110^{\circ}$. Time, 60 minutes.

The seventh dipping was red (roccelline). This colour was used pure and over the blueish gold of the previously dyed colours, it appeared a deep rich red, almost a bordeau. The turban, the vase, parts of the parrot's wings, the flowers in the foreground and the borders at the top and bottom of the panel are all in this tone. 
Temperature, $110^{\circ}$. Time, 50 minutes. After waxing all these parts, the other covered parts were inspected once more and all damaged places and objectionable cracks repaired; this completed, the panel was ready for the eighth and final bath, black.

At this stage the only parts of the whole design that were not covered in wax, were, the sky, a small part of the turban, the two panthers and the three little birds in the centre foreground.

The black was started pure, at a temperature of about $90^{\circ}$, and the piece remained in this bath about an hour; it was then taken out, the temperature brought up to $110^{\circ}$, blue added to the solution and the panel again dipped for another hour. The blue was added in order to improve the tone of the black. A solid blueblack was obtained in this way in place of the rusty black that would have been the result of dyeing straight black over the red. After the required intensity of tone had been reached, the piece was well rinsed and dried, preparatory to dipping in gasoline to remove the wax.

The making of this piece took about four 


\section{BATIKS, AND HOW TO MAKE THEM}

weeks, exclusive of the time taken to prepare the original sketch or the full-size cartoon.

About five pounds of pure bees-wax was used to cover all the surfaces, and fifteen gallons of gasoline were necessary to clean the piece. This is not surprising when one realizes the size of the panel, which was eight feet high and thirteen feet four inches wide; in all, 15,360 square inches. 


\section{INDEX}

$\mathbf{A}$

Acids, 70

Application of design, 50

C

Clean outline, 54

Colour groups, 64

Colour relation, 73

Composition of colour, the, 69

"Crackle," 37, 62

D

Difference in methods, 2

Different kinds of tjantings, 19

Dijesselhof, 27

Dutch artists of fame, 25

Dyes, 40

Dyes and dye manufacturers, 70

Dye tubs, 41

\section{E}

European use of batik, 29

Extracting colour, 66

F

Fabrics, 41

Folding material, 51
G

Gasoline, 56

Gasoline economy, 58

H

Handling the tjanting, 54

Head-dress, 4

Heating apparatus, 39

History, 24

$\mathrm{J}$

Javanese costume, 3

Javanese design, 5

$\mathrm{K}$

Kains, 3

L

Lebeau, 27

M

Matching colours, 72

$\mathrm{N}$

Native industry, 13

Native process, 15

$\mathbf{P}$

Painting in colours, 63 


\section{INDEX}

Precautions, 57

Preparing brushes, 36

Preparation of material, 50

Preventing the wax from sticking, 53

Price of native tjanting, 20 44

Primary and secondary col ours, 69

$\mathbf{R}$

Redrawing of design, 52

Removing stain, 40

Rewaxing, 62

Rinsing, 61

$\mathbf{S}$

Slendang, 4
Streaks in dyeing, 61

$\mathbf{T}$

Temperature of dye-bath, 59

Tertiary colours, 71

Tjantings, 32

Tjaps, 7

$\mathbf{U}$

Use of brush, 36

Use of too much dye, the, 60

W

Wax mixtures, 37 



\section{0,}

7

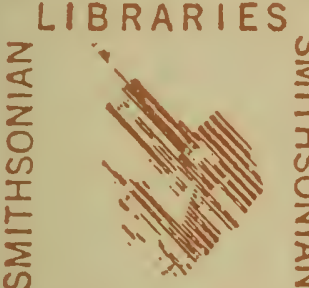

ION NOILNIIISNI
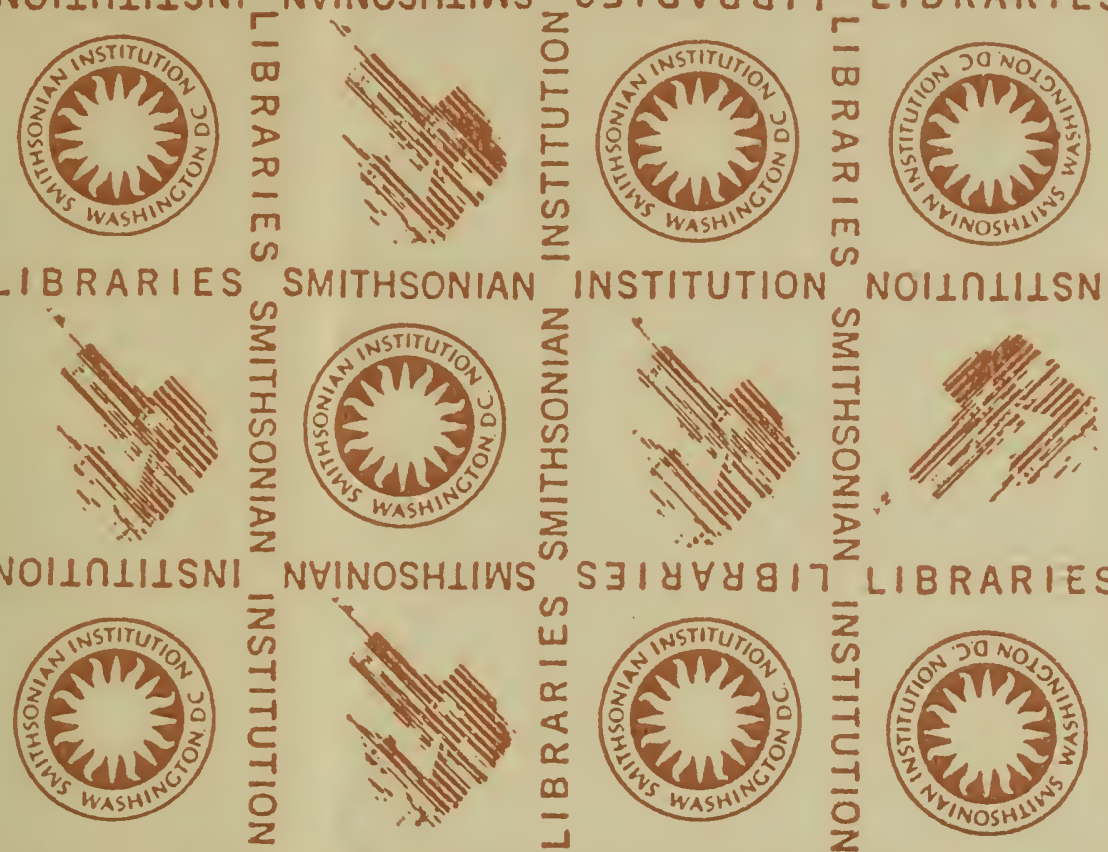

$\frac{0}{2}$
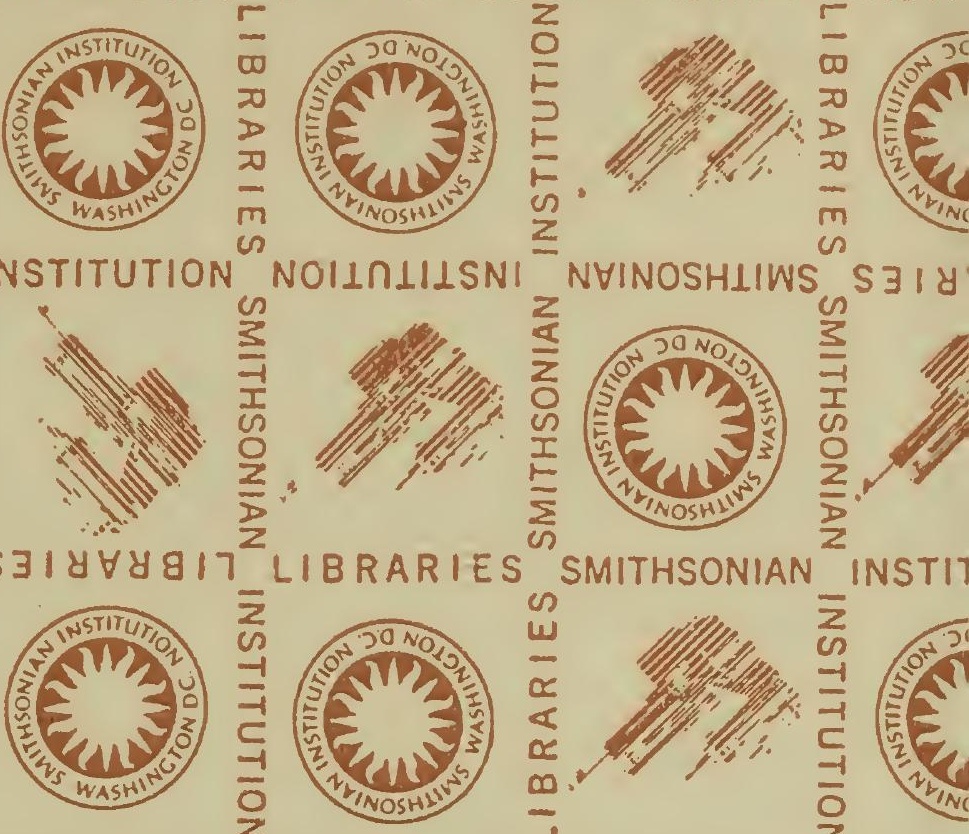

$\frac{5}{2}$
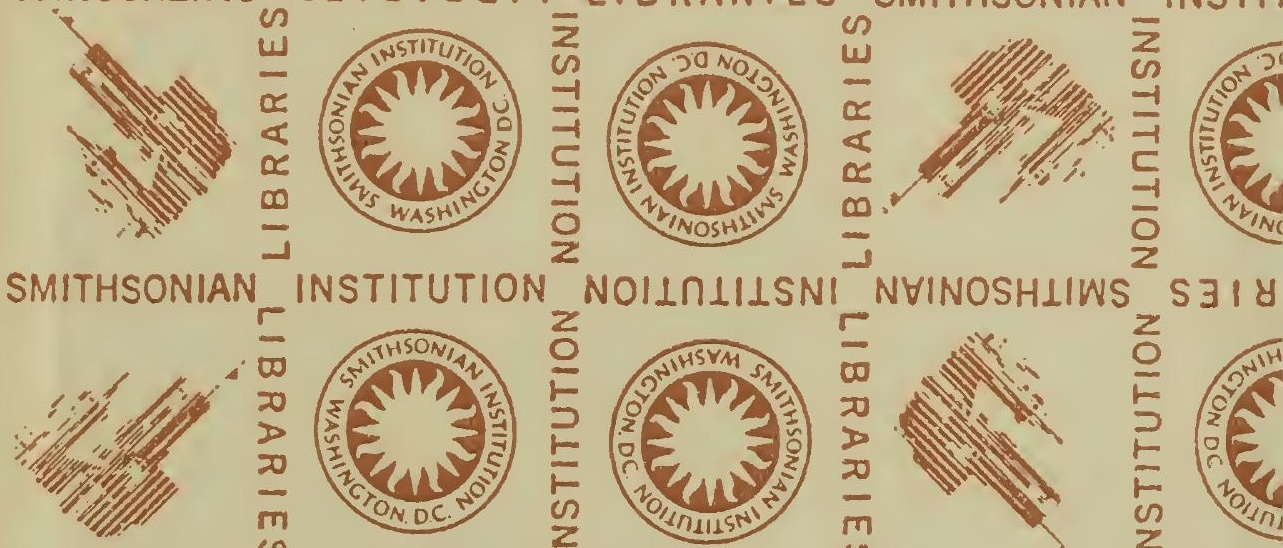

NVINOSHLIWS SJIV
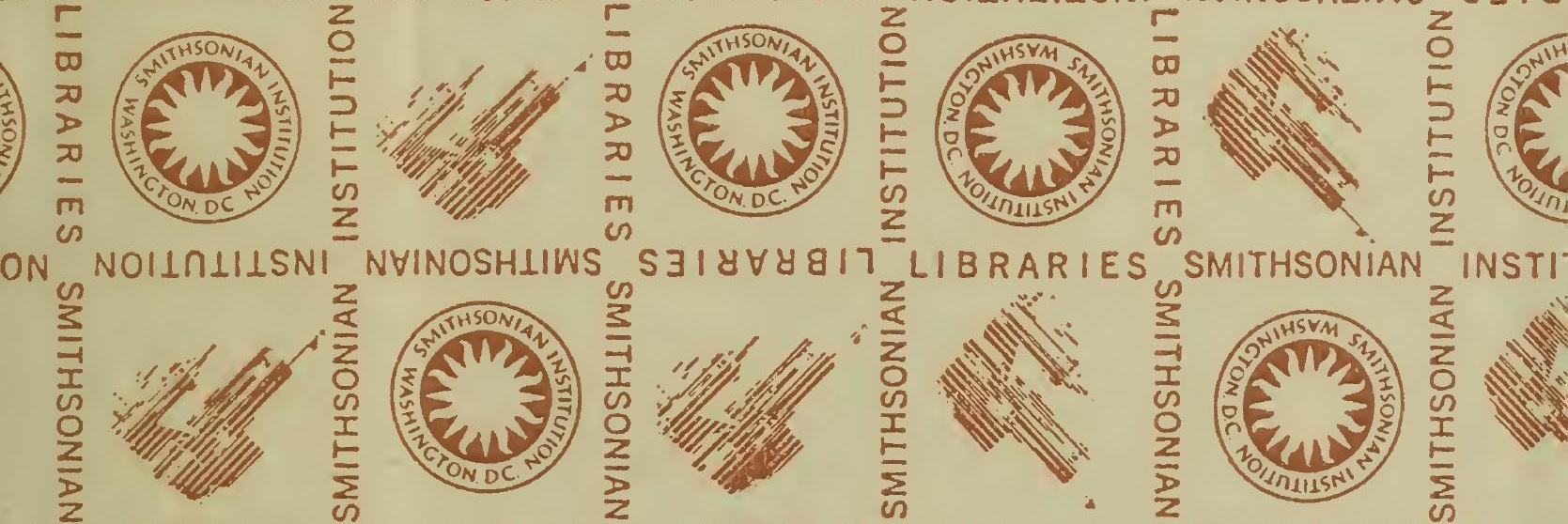

is
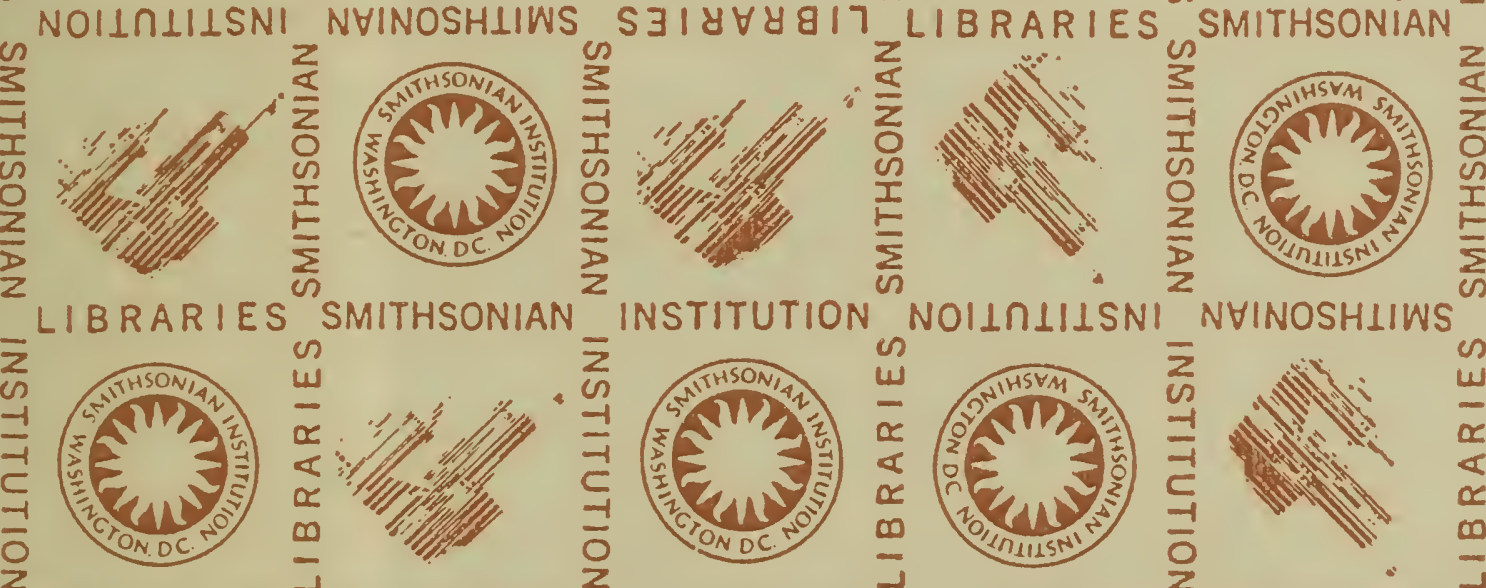

5318
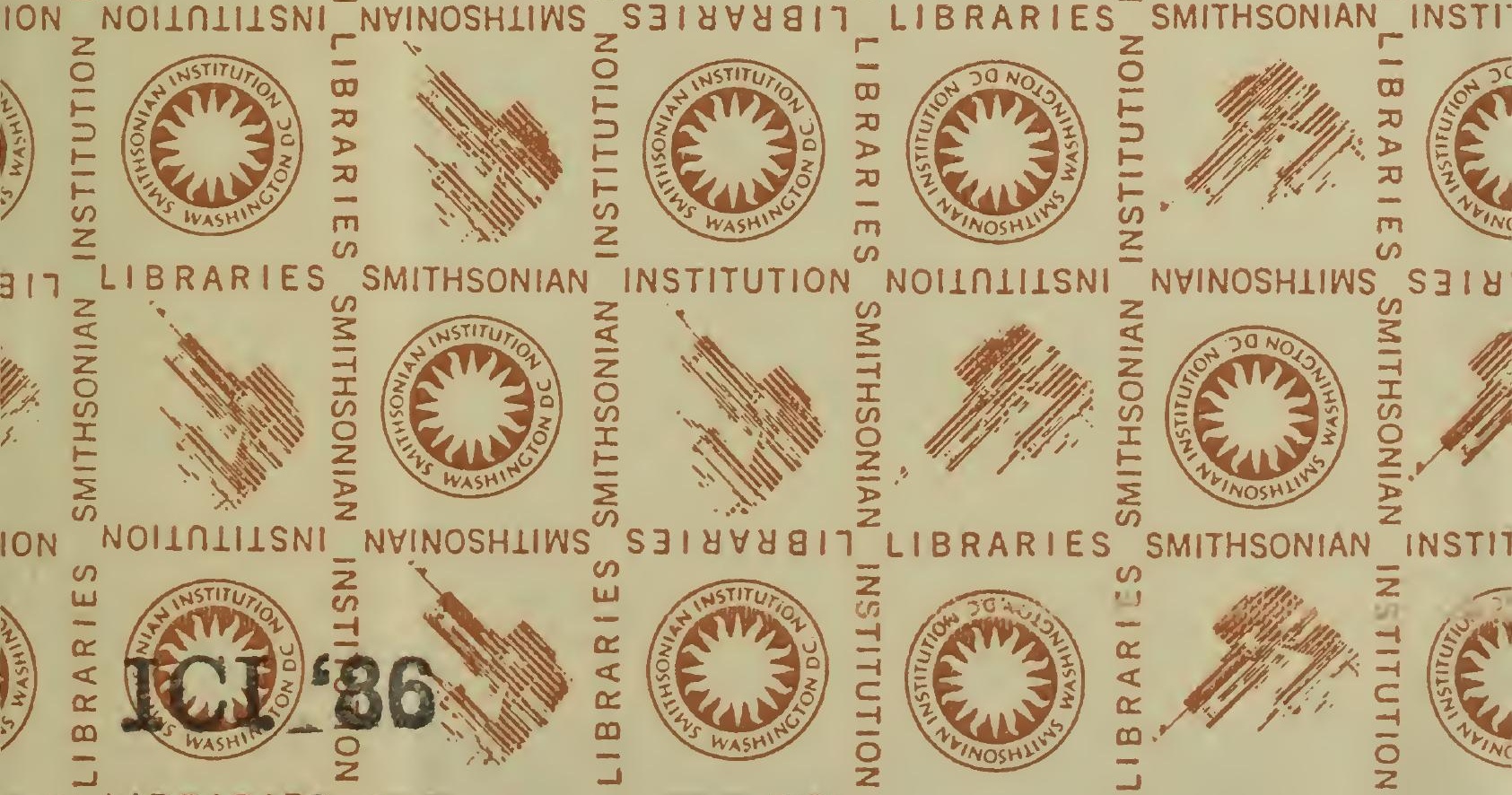
